Review Article

\title{
Dietary Phytochemicals: Natural Swords Combating Inflammation and Oxidation-Mediated Degenerative Diseases
}

\author{
Md. Asiful Islam, ${ }^{1}$ Fahmida Alam, ${ }^{1}$ Md. Solayman, ${ }^{2}$ Md. Ibrahim Khalil, ${ }^{1,2}$ \\ Mohammad Amjad Kamal, ${ }^{3,4,5}$ and Siew Hua Gan ${ }^{1}$ \\ ${ }^{1}$ Human Genome Centre, School of Medical Sciences, Universiti Sains Malaysia, 16150 Kubang Kerian, \\ Kelantan, Malaysia \\ ${ }^{2}$ Department of Biochemistry and Molecular Biology, Jahangirnagar University, Savar, Dhaka 1342, Bangladesh \\ ${ }^{3}$ King Fahd Medical Research Center, King Abdulaziz University, P.O. Box 80216, Jeddah, Saudi Arabia \\ ${ }^{4}$ Enzymoics, 7 Peterlee Place, Hebersham, NSW 2770, Australia \\ ${ }^{5}$ Novel Global Community Educational Foundation, 7 Peterlee Place, Hebersham, NSW 2770, Australia \\ Correspondence should be addressed to Md. Asiful Islam; ayoncx70@yahoo.com and Siew Hua Gan; shgan@usm.my
}

Received 13 May 2016; Revised 8 July 2016; Accepted 22 August 2016

Academic Editor: Yolanda de Pablo

Copyright ( $(2016 \mathrm{Md}$. Asiful Islam et al. This is an open access article distributed under the Creative Commons Attribution License, which permits unrestricted use, distribution, and reproduction in any medium, provided the original work is properly cited.

\begin{abstract}
Cumulatively, degenerative disease is one of the most fatal groups of diseases, and it contributes to the mortality and poor quality of life in the world while increasing the economic burden of the sufferers. Oxidative stress and inflammation are the major pathogenic causes of degenerative diseases such as rheumatoid arthritis (RA), diabetes mellitus (DM), and cardiovascular disease (CVD). Although a number of synthetic medications are used to treat these diseases, none of the current regimens are completely safe. Phytochemicals (polyphenols, carotenoids, anthocyanins, alkaloids, glycosides, saponins, and terpenes) from natural products such as dietary fruits, vegetables, and spices are potential sources of alternative medications to attenuate the oxidative stress and inflammation associated with degenerative diseases. Based on in vitro, in vivo, and clinical trials, some of these active compounds have shown good promise for development into novel agents for treating RA, DM, and CVD by targeting oxidative stress and inflammation. In this review, phytochemicals from natural products with the potential of ameliorating degenerative disease involving the bone, metabolism, and the heart are described.
\end{abstract}

\section{Introduction}

Degenerative diseases occur due to the continuous deterioration of cells and tissues that ultimately affects major organs. Both oxidative stress and inflammation are considered major role players in the pathogenesis of chronic degenerative diseases including cardiovascular diseases (CVDs) [1], diabetes mellitus (DM) [2], and rheumatoid arthritis (RA) [3]. All chronic degenerative diseases exert an immense impact on the global health economy [4-6]. Currently, although several synthetic regimens are used to attenuate oxidative stress and inflammation-mediated degenerative diseases, none are free from side effects when utilized in the treatment of CVDs [7], DM [8], or RA [9].
Over the last two decades, tremendous experimental advancements have been made in the use of natural products against different types of degenerative diseases targeting oxidative stress and inflammation [10]. Many studies have also demonstrated that phytochemicals are important therapeutic agents targeting oxidative stress and inflammation, which are the major culprits in the pathogenesis of chronic degenerative diseases $[11,12]$. Some of these phytochemicals are good candidates for future drug discovery and development to treat degenerative diseases [13-16].

In this review, we discussed the pathogenesis of CVDs, $\mathrm{DM}$, and RA, which involve the heart, metabolism and the joints, respectively, and we discussed the use of phytochemicals (which are synthesized by fruits, vegetables, and 
spices) in attenuating the oxidative stress and inflammation associated with these chronic diseases.

\section{Methodology}

The PubMed database was systematically searched to retrieve evidence of potential dietary natural products (fruits, vegetables, and spices) and their active substances (antioxidants, polyphenols, carotenoids, anthocyanins, alkaloids, glycosides, saponins, and terpenes) for use against CVDs, DM, and RA by attenuating oxidative stress and inflammation (see Appendix). To retrieve clinical and experimental evidences of dietary phytochemicals associated with CVDs, DM, and RA, only papers published in English between January 2000 and March 2016 were considered.

\section{Cardiovascular Diseases}

CVDs are a group of diseases associated with complications of the heart and blood vessels; most are associated with coronary heart disease. Major risk factors of CVDs include hypertension (HTN), hypercholesterolemia, diabetes, obesity, inflammation, smoking, consumption of alcohol, lack of exercise, and a familial history of heart diseases [17, 18].

CVD is believed to be the major contributor to worldwide mortality and morbidity in both developed and developing countries. In 2012, it was estimated that 17.5 million people died from CVDs, which represents $31 \%$ of all global deaths. Among these deaths, it was estimated that 7.4 million were due to coronary heart disease. It has also been predicted that, by 2030, over 28 million people will die from CVDs [19]. Based on the American Heart Association Report (2016), 85.6 million American adults were afflicted with CVDs, and this number is anticipated to rise and add a greater economic burden to the overall health care system [4].

3.1. Pathogenesis. The pathogenesis of CVDs is multifactorial, resulting from the interplay of genetic and environmental factors. However, atherosclerosis, which occurs due to the accumulation of atherosclerotic plaques within the walls of the arteries (Figure 1), is believed to be the major precursor of CVDs.

Plaque formation is initiated by endothelial damage and is followed by the adherence of circulating monocytes and subsequent exposure to homocysteine, inflammation, increased platelet aggregation, and higher levels of oxidized low density lipoprotein (LDL-ox) and reactive oxygen species (ROS) [20]. In addition, increased serum lipids such as triglycerides (TG) and cholesterol (C), increased plasma fibrinogen and coagulation factors, abnormal glucose metabolism, and hypertension play crucial roles in the pathogenesis of CVDs [21]. Adherent monocytes differentiate into macrophages, which ingest LDL-ox and transform into large foam cells, appearing as a fatty streak.

Additionally, although intact endothelium can prevent smooth muscle proliferation by releasing nitric oxide (NO) when the endothelium is damaged, smooth muscle proliferation and migration are observed from the tunica media into the tunica intima in response to damaged endothelial cell-secreted cytokines. This activity induces the formation of a fibrous capsule covering the fatty streak. Due to calcification in the smooth muscle cells and on the unstable fatty streak, plaque hardening occurs, which further blocks the coronary arteries [22, 23].

Further, genetic alterations can adversely promote the development of CVDs. Some examples include mutations or allelic variations of the renin-angiotensin pathway, endothelial NO synthase, coagulation factors, and fibrinogen, which can lead to the development of atherosclerosis [24]. In addition, diets that are high in saturated fat, trans-fats, and salt; diets that are low in fruits, vegetables, and fish; smoking; the consumption of tobacco; and insufficient physical activity are cardiovascular risk factors $[25,26]$. High density lipoprotein (HDL) levels are negatively correlated with CVDs; therefore, the consumption of fiber-rich diets, including fruits and vegetables, the control of high blood pressure, proper regulation of lipid and lipoprotein metabolism, decreased platelet aggregation, and increased antioxidant status should limit the progress of CVDs.

3.2. The Role of Dietary Phytochemicals. Although there are several synthetic regimens available for treating CVDs, none are free of side effects and limitations (Table 1). Over the last two decades, researchers confirmed that the consumption of regular fresh fruits, vegetables, and spices has the potential to lower CVD risks by attenuating oxidative stress and inflammatory mediators. Here, we discuss some of the potential experimental and clinical evidence (Table 2) in favor of treating CVDs by supplementation with fruits, vegetables, and spices.

3.2.1. Fruits. A population-based prospective cohort study from nine areas in Japan (77,891 male and female subjects aged 45-74 years) suggested that fruit consumption protects against the risk of CVDs [27]. A meta-analysis by Wang et al. [28] provided evidence that a higher consumption of fruits and vegetables correlated with a lower risk of all-cause mortality, predominantly cardiovascular mortality. A crosssectional study on Hispanic $(n=445)$ and non-Hispanic white elders $(n=154)$ found that the high-frequency consumption of fruits and vegetables lowered plasma Creactive protein (CRP) and homocysteine concentrations, consequently reducing inflammation, which is considered the major risk factor of CVDs [29]. Recently (2016), a study on a Chinese population (512,891 adults ranging from 30 to 79 years old) from 10 diverse localities also revealed that a high level of fruit consumption was associated with decreased HTN and blood glucose levels, which significantly decrease the risks of CVDs [30]. Another study by van't Veer et al. [31] on a Dutch population reported that cardiovascular deaths could be reduced by $16 \%$ (approximately 8,000 deaths per year), ranging from $6 \%$ to $22 \%$, through high intake of fruits and vegetables. A number of randomized controlled trials have also been conducted in previous years (Table 2), where fruits, vegetables, and spices have proven beneficial for CVD management.

Apple is one of the most commonly consumed fruits, and its polyphenolic extract has a significant effect on decreasing 


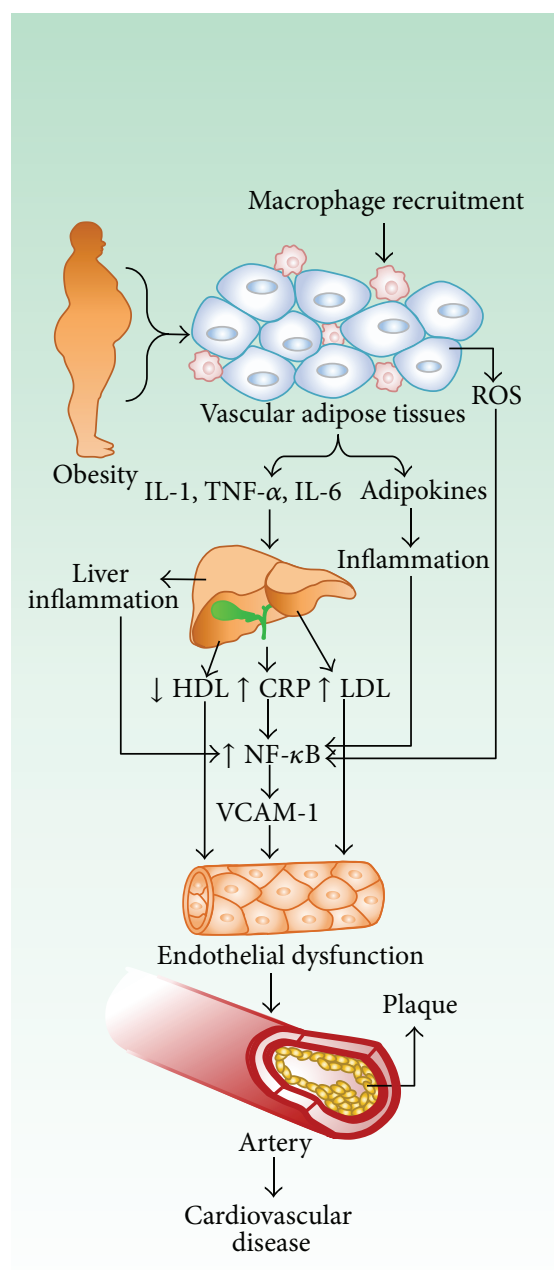

(a) Cardiovascular disease

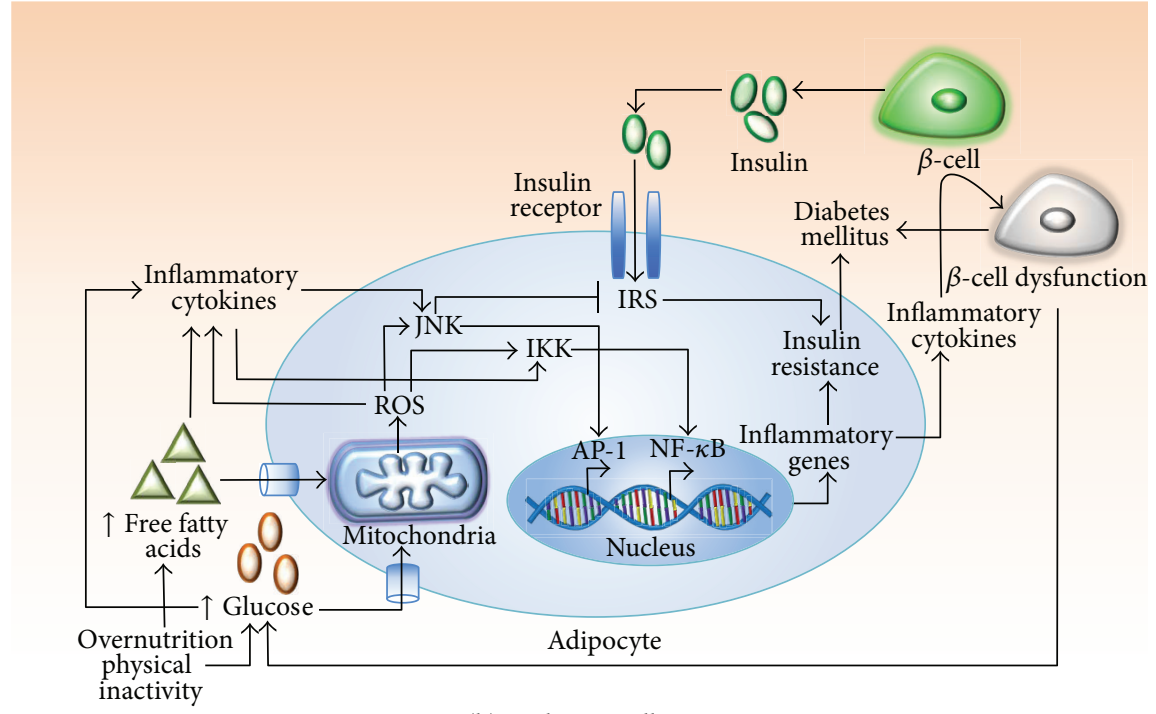

(b) Diabetes mellitus

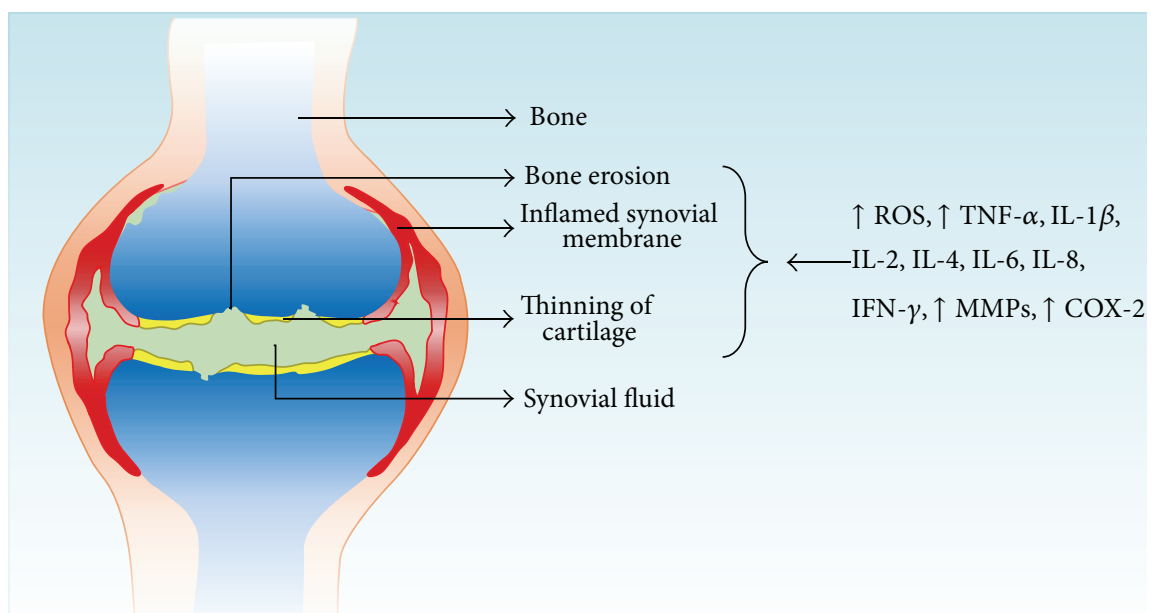

(c) Rheumatoid arthritis

FIGURE 1: Inflammation and oxidative stress-mediated pathogenesis of (a) cardiovascular disease, (b) diabetes mellitus, and (c) rheumatoid arthritis.

the serum total-C and LDL-C levels in healthy individuals with relatively high body mass index (BMI), which consequently limits CVD risk [32]. Another study showed that the consumption of banana decreased the oxidative modification of LDL, plasma lipids, and lipoproteins and thus ultimately aids in protection from atherogenesis due to its antioxidant properties [33]. In addition, berry fruits (blueberries, strawberries, and cranberries) can also reduce cardiovascular risk factors such as lipid peroxidation, inflammation, and the control of HTN due to the presence of high levels of anthocyanins and ellagitannins in their skin and flesh [3436]. In addition, for being good sources of polyphenols, berries are rich in micronutrients such as folate, $\alpha$-carotene, $\beta$-carotene, potassium, vitamin $\mathrm{C}$, and vitamin $\mathrm{E}$, which exhibit noteworthy antioxidant activities [37].

Several studies have shown that citrus fruits such as mandarins, lemons, oranges, and grapefruits contain high quantities of flavanones (e.g., naringin and hesperidin) that improve significant vascular functions and the lipid profile in patients with coronary artery diseases [38-40]. The delicious pomegranate fruit and its juice and peel extracts have antihypertensive, antiatherosclerotic, antioxidant, and antiinflammatory effects due to the presence of polyphenolic compounds including anthocyanins, catechins, and tannins, which contribute to the attenuation of CVD risk factors [41, 42].

The consumption of polyphenol-rich peach and plum juice showed preventive effects against risk factors for cardiometabolic disorders. This protection was largely achieved by decreasing the expression of plasma proatherogenic and proinflammatory molecules, intercellular cell adhesion molecule-1 (ICAM-1), monocyte chemotactic protein-1, and nuclear factor kappa B (NF- $\kappa \mathrm{B}$ ) and by decreasing foam cell adherence to aortic arches. In addition, the ingestion 


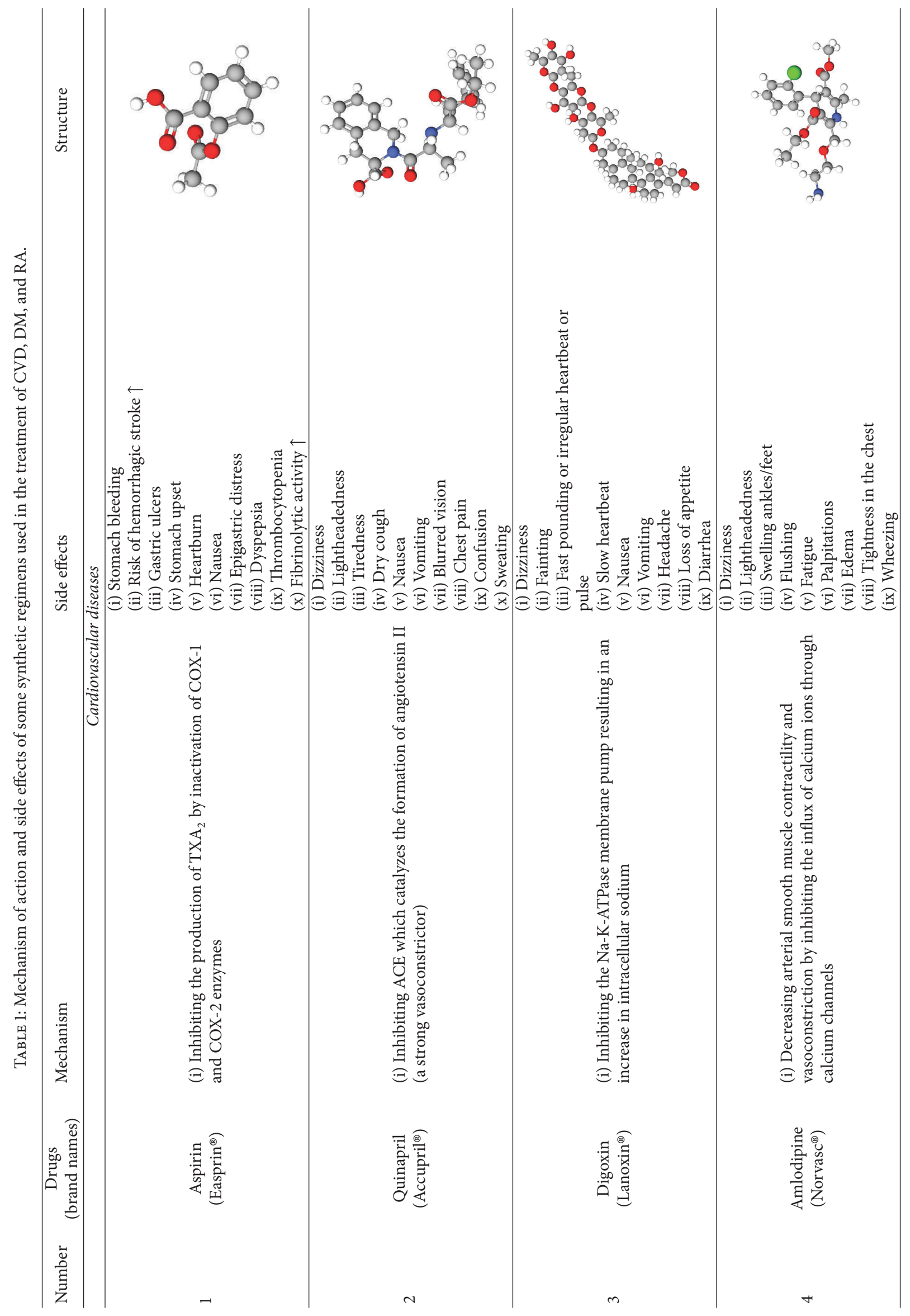




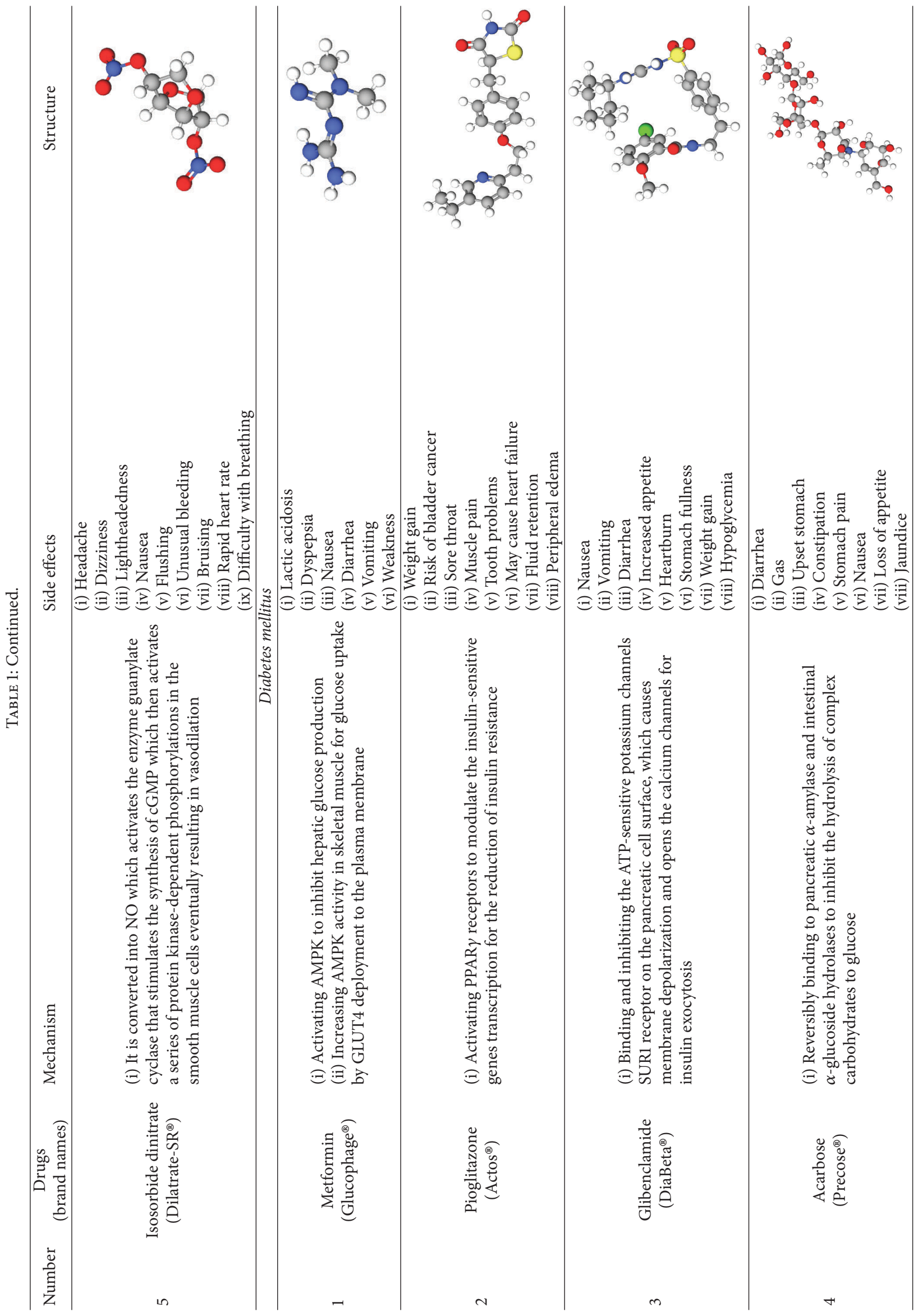




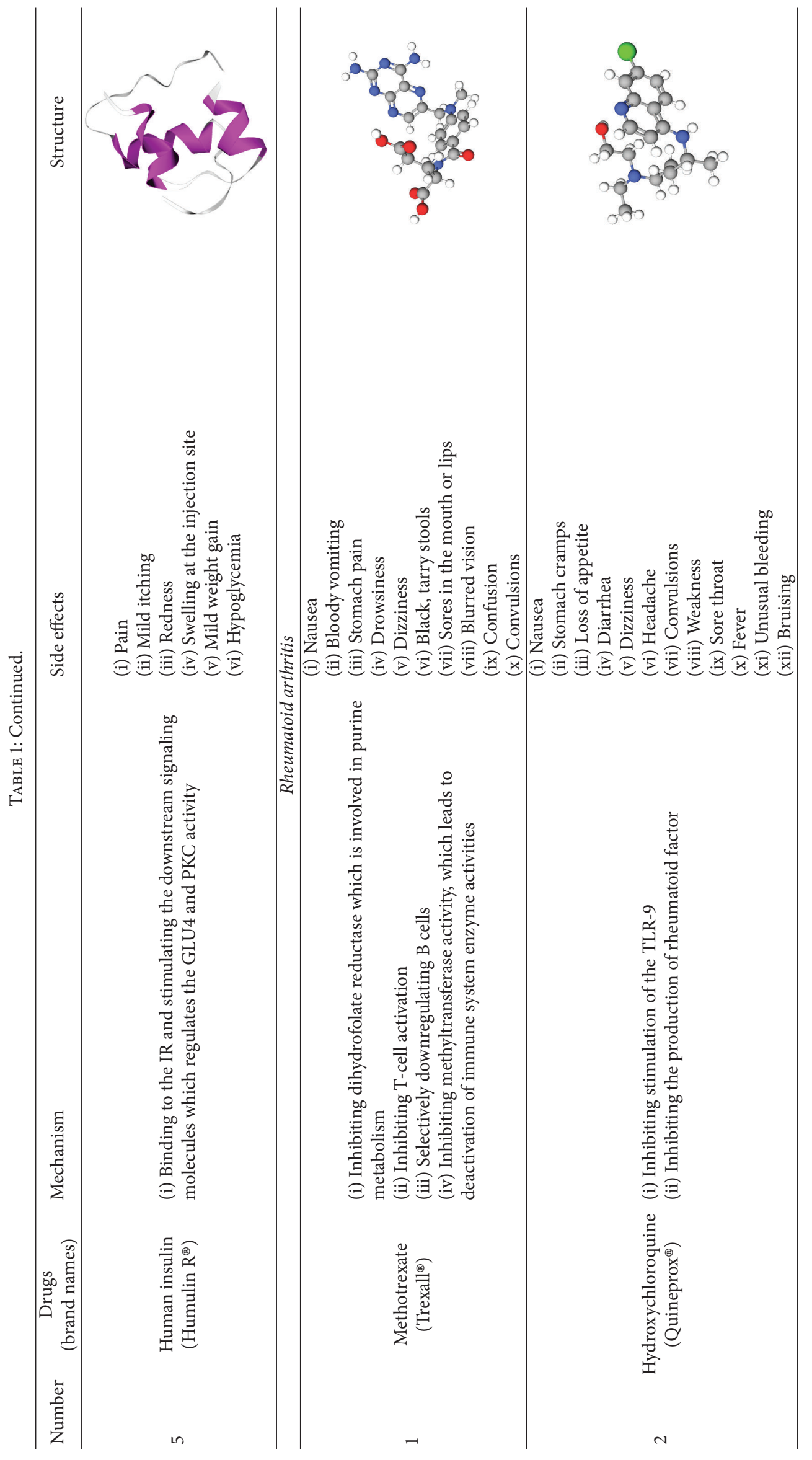




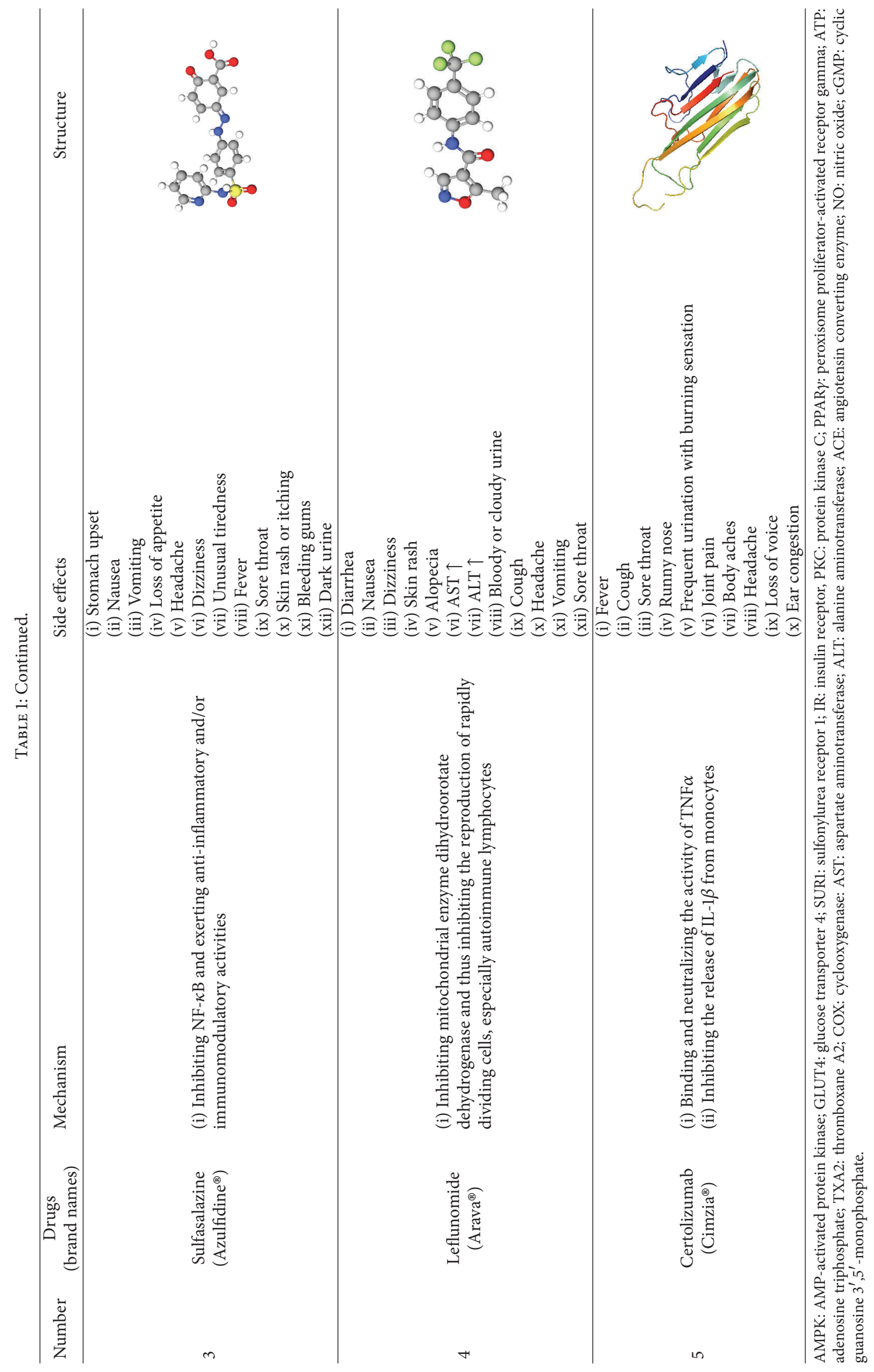




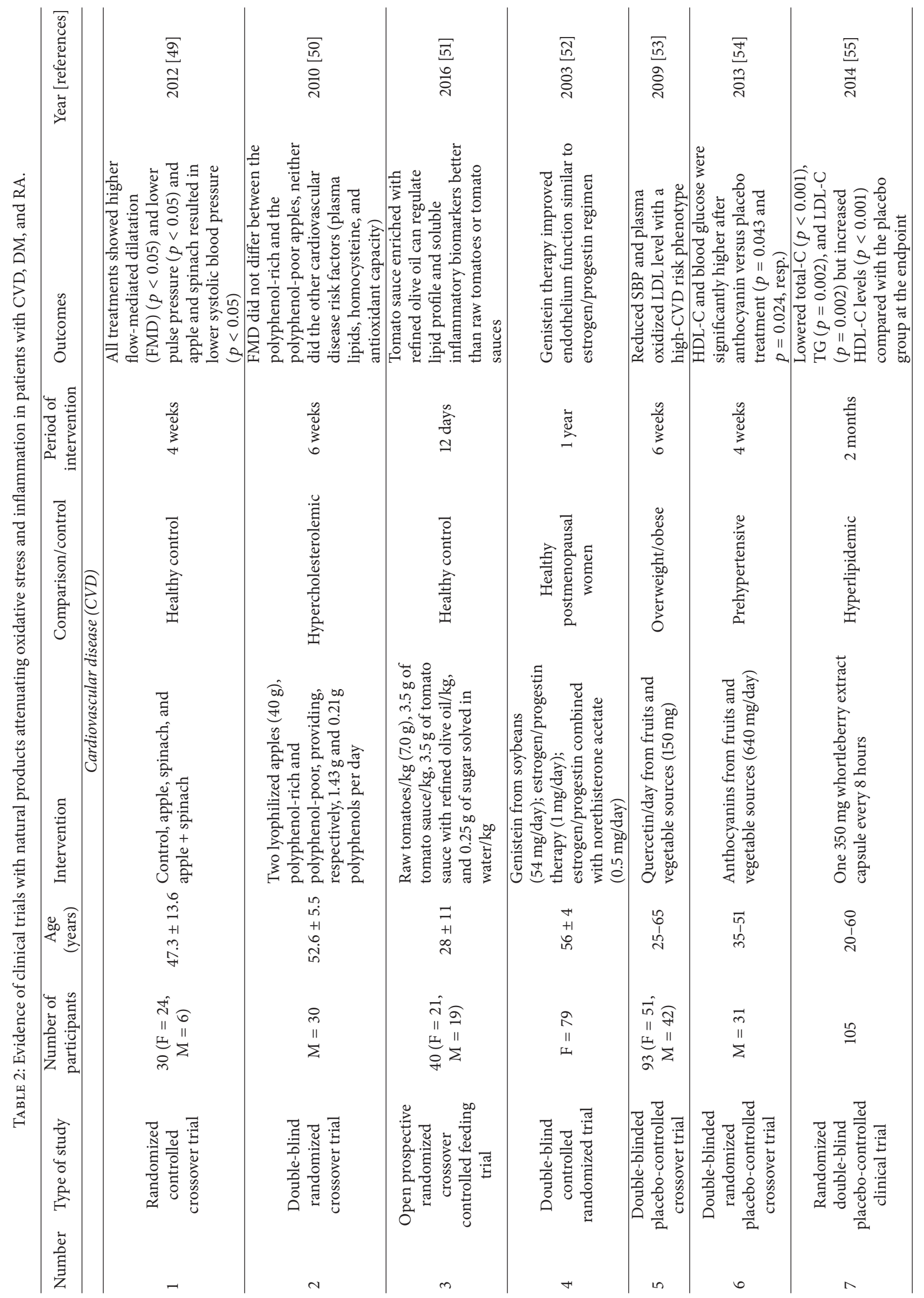




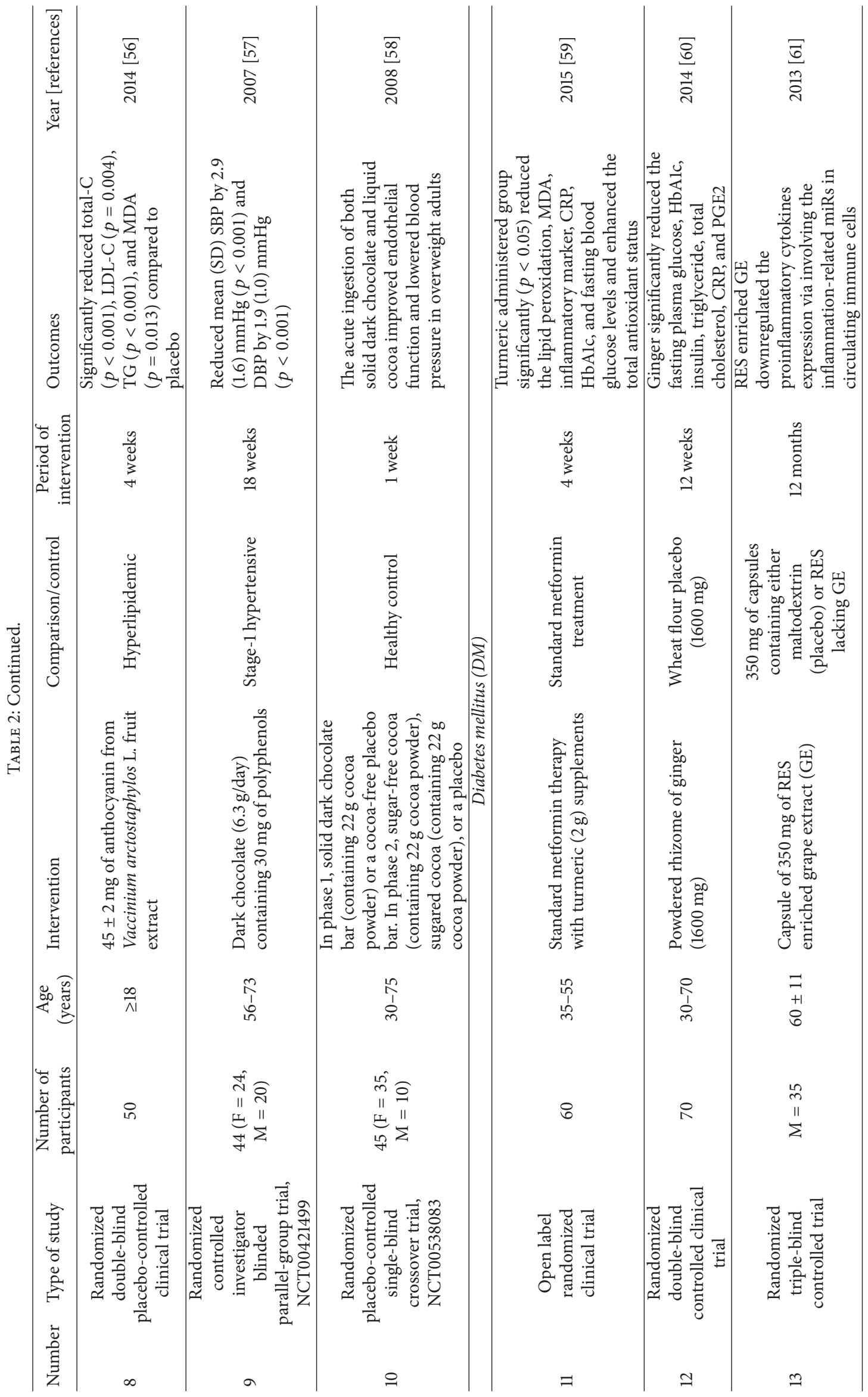




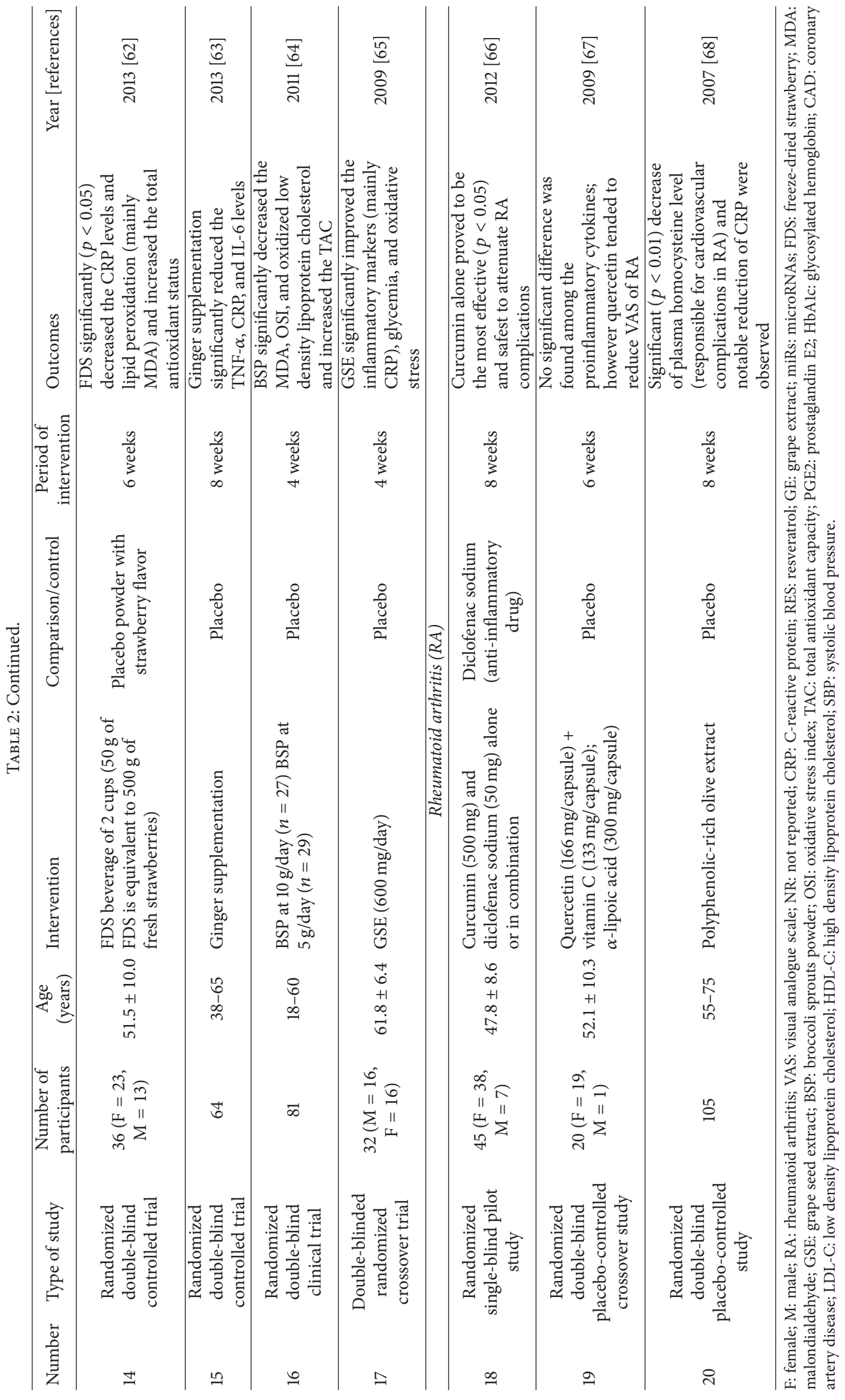


of peach and plum juice reduced angiotensin II levels in plasma and reduced the expression of its receptor Agtr1 in cardiac tissues, thus demonstrating the ability of peach and plum polyphenols to act as peroxisome proliferatoractivated receptor- $\gamma$ (PPAR $\gamma)$ agonists [43]. An in vivo and ex vivo experiment by Hong et al. demonstrated that watermelon improved lipid profiles and antioxidant capacity and decreased inflammation, thus altering gene expression for lipid metabolism and consequently reducing the risk factors for CVDs [44].

3.2.2. Vegetables. A group of widely consumed flavonoids present in vegetables exhibit some protective activities against CVD progress [45]. Sulfur-containing organic compounds (organosulfur) from garlic (Allium sativum), onion (Allium сера), and cruciferous vegetables such as broccoli, cauliflower, cabbage, and Brussels sprouts showed cardioprotective effects mediated by their antioxidant and anti-inflammatory properties [46]. Moreover, experimental studies on garlic suggested the blocking of platelet aggregation through ADP and platelet-activating factor (PAF) inhibition [47]. A key flavonoid from onion, quercetin $\left(3,3^{\prime}, 4^{\prime}, 5,7\right.$-pentahydroxyflavone), exerts antiatherosclerotic effects, and its metabolites, which showed antioxidant and anti-inflammatory activities, accumulate in the aorta tissue [48].

Upaganlawar et al. [69] showed that lycopene, a bright red carotene and carotenoid pigment in tomato, considerably reduced myocardial infarction (MI) in isoproterenol-induced rats because of its antioxidant activities. A recent study (2015) also demonstrated that the supplementation of tomato with corn oil improved diastolic function, changed cardiac miRNA expression, and attenuated both lipid hydroperoxidation and oxidative stress [70]. Similarly, tomato-based products such as tomatoes, tomato sauce, and tomato juice had cardiovascular advantages due to the presence of dietary lycopene [71].

3.2.3. Spices. Several studies have observed that the widely used spice ginger (Zingiber officinale) helps in the treatment of CVDs. Ginger exhibits anti-inflammatory as well as antithrombotic properties by inhibiting the production of NO, inflammatory cytokines, cyclooxygenase (COX), and lipoxygenase (LOX), and it shows no or very few side effects, unlike nonsteroidal anti-inflammatory drugs (NSAIDs) [72, 73]. Ginger also displays antioxidant [74], antiplatelet [75], positive inotropic [76], hypotensive [77], and hypoglycemic and hypolipidemic effects [78] in in vitro and in vivo studies and human clinical trials. One of the most regularly consumed spices, black pepper, and its active principle (piperine) showed significant decreases in the levels of $\mathrm{C}$, free fatty acids, phospholipids, and triglycerides and an increase in the concentration of high density lipoprotein cholesterol (HDLC), thus reducing the risk of atherosclerosis $[79,80]$. Another spice called saffron (Crocus sativus L.) and its essential oil-like constituent safranal show remarkable cardioprotective effects in isoproterenol-induced MI Wistar rats by maintaining the redox status of the cell $[81,82]$. Cinnamon is another spice that is abundantly found in Bangladesh, India, China, Sri Lanka, Egypt, and Australia; the leaves and barks of cinnamon are used widely in food or to yield essential oils, and they show cardioprotective effects [83].

3.2.4. Miscellaneous. A meta-analysis reported that the consumption of $1 \mathrm{cup} /$ day of green tea could decrease by $10 \%$ the chance of developing coronary artery disease due to the presence of polyphenols such as catechins, epicatechin 3-gallate (ECG), and epigallocatechin (EGC) and thereby prevent CVD; however, no significant relationship was found between black tea polyphenols and cardioprotective effects [84].

Chocolate, cocoa, and cocoa products provide a substantial quantity of dietary polyphenols. There is numerous evidence from in vivo and ex vivo experiments as well as clinical studies showing the roles of these products in protecting against the risk factors of CVDs. A cross-sectional study by Buijsse et al. [85] showed that the consumption of cocoa-containing foods was inversely related to the blood pressure and 15-year cardiovascular mortality. Several metaanalyses have also established that the consumption of cocoa could modulate multiple cardiovascular risk factors such as flow-mediated vascular dilatation, activation of platelets [86], insulin resistance [87], and the blood C level [88].

Because CVD is a multifactorial disorder, the consumption of fruits, vegetables, spices, green tea, red wine, or other polyphenol-rich phytochemicals is expected to decrease the risk of CVD via multiple mechanisms to ensure a healthy life.

\section{Diabetes Mellitus}

DM is a group of metabolic diseases that are caused by overnutrition (mainly high-fat diet) and a lack of physical activity [89]. In healthy individuals, active pancreatic $\beta$-cells secrete insulin to reduce glucose levels in insulin-sensitive liver, muscle, and adipose tissues [90]. In type 1 diabetes mellitus (T1DM), defective insulin secretion occurs due to dysfunctional pancreatic $\beta$-cells or a decrease in $\beta$-cell mass over time, whereas in type 2 diabetes mellitus (T2DM), insulin-stimulated glucose uptake in hepatic and adipose tissues is reduced due to insulin resistance [91]. Over time, insulin resistance tends to increase with age. In contrast, $\beta$-cells that initially produce insulin in sufficient quantities eventually produce insufficient quantities, thereby leading to the onset and progression of diabetes [92].

Worldwide, DM is the most common endocrine disorder; the reported prevalence in 2013 was 382 million people, which is anticipated to increase to as many as 592 million by 2035 [93]. The majority (80\%) of DM patients are from low and middle income countries, where the incidence of DM is expected to increase in the next 22 years [93].

4.1. Pathogenesis. Chronic low-grade inflammation and the activation of the innate immune system are considered to be closely involved in the pathogenesis of DM [94]. Excessive levels of nutrients (glucose and free fatty acids) initiate cellular stress in the pancreatic islets and insulin-sensitive tissues including adipose tissue, leading to the activation of c-Jun N-terminal kinase (JNK) and NF- $\kappa \mathrm{B}$ (Figure 1) [95]. The inflammatory signaling pathways regulate protein 
phosphorylation and cellular transcriptional events, thereby increasing the adipocyte production of proinflammatory cytokines, including tumor necrosis factor alpha (TNF- $\alpha$ ), interleukin (IL) 6 , IL-1 $\beta$, leptin, resistin, and chemokines such as MCP-1, CC-chemokine ligand 2 (CCL2), CCL3, and CXC-chemokine ligand 8. As a result, immune cells such as monocytes are recruited to the adipose tissues, thus contributing to tissue inflammation. The monocytes that differentiate into macrophages produce several inflammatory cytokines, further promoting local inflammation. In addition, the release of cytokines and chemokines from the adipose tissues into the circulation promotes inflammation in other tissues including the islets [95].

Both JNK and IKK $\beta / \mathrm{NF}-\kappa \mathrm{B}$ play important roles in inflammation-induced insulin resistance. JNK is a stress kinase that normally phosphorylates the c-Jun component of the AP-1 transcription factor and promotes insulin resistance through the phosphorylation of serine residues in insulin receptor substrate 1 (IRS-1) [96]. Insulin receptor signaling that normally occurs through a tyrosine kinase cascade [90] is inhibited by counter-regulatory serine/threonine phosphorylation [97]. IKK $\beta$ is highly selective towards its physiological substrates, the $\mathrm{I} \kappa \mathrm{B}$ protein inhibitors of NF$\kappa \mathrm{B}$. Phosphorylation by IKK $\beta$ targets $\mathrm{I} \kappa \mathrm{B} \alpha$ for proteasomal degradation, which liberates NF- $\kappa \mathrm{B}$ for translocation into the nucleus, where it promotes the expression of numerous target genes whose products induce insulin resistance. IKK $\beta$ causes insulin resistance through the transcriptional activation of NF- $\kappa$ B. Therefore, anti-inflammatory therapies have the potential to decrease gene expression and improve insulin resistance.

Increasing adiposity is reported to increase inflammatory gene expression in the liver [98], which further increases the production of cytokines and chemokines. Immune cells including monocytes and macrophages are recruited and/or activated, which leads to local insulin resistance. Alternatively, the portal delivery of abdominal fat-derived cytokines and lipids contributes to hepatic inflammation. However, NF$\kappa \mathrm{B}$ is activated in hepatocytes, causing the overproduction of cytokines including IL- 6, TNF- $\alpha$, and IL- $1 \beta$ in fatty liver. The proinflammatory cytokines then contribute to the development of insulin resistance in skeletal muscle and other tissues [95].

Oxidative stress contributes to DM by modifying the enzyme systems, impairing glutathione metabolism and lipid peroxidation and reducing vitamin C levels [99]. In fact, a close relationship exists between hyperglycemia and oxidative stress in DM. Hyperglycemia fuels glucose autooxidation, NADPH oxidase activity, oxidative phosphorylation, protein glycation, and the polyol pathway, which leads to ROS generation and oxidative stress (Figure 1) [100]. ROS attack the healthy cells by damaging the functional and structural integrity of the cells, which consequently leads to many pathophysiological conditions [101].

4.2. The Role of Dietary Phytochemicals. Several groups of synthetic drugs and insulin possess antioxidative and antiinflammatory potential that can be used in the treatment of DM. Unfortunately, none are free from adverse effects
(Table 1). Therefore, the quest for alternative and safer treatment regimens for DM is ongoing. In this review, successful clinical trials based on intervention with fruits, vegetables, and spices are considered (Table 2), and in vivo and in vitro experiments using the phytochemicals from these dietary sources that have exhibited potential to attenuate oxidative stress and inflammation for DM treatment are discussed.

4.2.1. Fruits. Numerous in vivo and in vitro experiments with fruits, fruit products, and fruit-derived compounds have been extensively conducted for DM management. The oral administration of naringin $\left(4^{\prime}, 5,7\right.$-trihydroxyflavonone7 -rhamnoglucoside) at $50 \mathrm{mg} / \mathrm{kg} /$ day is reported to reduce oxidative stress and increase fasting plasma insulin in streptozotocin- (STZ-) induced diabetic Sprague Dawley rats. Naringin is considered to be the main flavonoid in grapefruit juice, and it is thought to ameliorate oxidative stress through its antioxidant effects, thereby improving ATP synthesis in pancreatic $\beta$-cell mitochondria and ameliorating the subsequent insulin secretion by $\beta$-cells [102]. Another study also investigated the effect of naringin treatment (25, 50 , and $100 \mathrm{mg} / \mathrm{kg} /$ day) on diabetic Wistar albino male rats for 28 days. Naringin significantly ameliorated $\beta$-cell dysfunction, insulin resistance, and hyperglycemia, reduced TNF- $\alpha$, IL-6, CRP, and antioxidant enzyme activities and $\mathrm{NF}-\kappa \mathrm{B}$ expression, and increased adiponectin and PPAR $\gamma$ expression. Additionally, naringin effectively rescued kidney cells, $\beta$-cells, and liver cells from further pathological modifications and oxidative damage [103].

Resveratrol, a naturally occurring polyphenol found in grapes and red wine, has recently been shown to exert potent antidiabetic, antioxidative, and anti-inflammatory activities. In the liver and spleen of STZ-induced male Long-Evans rats (type 1 diabetic animal models), resveratrol treatment (0.1 or $1.0 \mathrm{mg} / \mathrm{kg} /$ day) for 7 days significantly reduced oxidative stress (including superoxide anion content, protein carbonyl level, and manganese-superoxide dismutase expression) in hepatic and splenic tissues, and it reduced hepatic inflammation (NF- $\kappa$ B and IL- $1 \beta$ ) and decreased the TNF- $\alpha$ and IL- 6 levels in diabetic spleen [104].

Phlorizin (PZ) is a predominant phenolic compound that is found in apples. Preexposure to docosahexaenoic acid ester of PZ (PZ-DHA) in inflammation-induced macrophages [stimulated by lipopolysaccharide (LPS)] was effective in reducing the TNF- $\alpha$, IL- 6 , and COX-2 protein levels compared with DHA. Both PZ-DHA ester and DHA have the potential to inhibit NF- $\kappa \mathrm{B}$ activation. Therefore, PZ-DHA ester has the potential to be used in T2DM-associated inflammation [105].

Diabetes mellitus is associated with the reduction of glutathione levels, thus indicating the critical role of oxidative stress in its pathogenesis. In Ins-1E pancreatic $\beta$-cells, pretreatment with the flavonoid epicatechin (present in green tea, grapes, and cocoa) prevented tert-butyl hydroperoxideinduced cell damage, ROS, and p-JNK expression. In addition, it restored insulin secretion which indicates the protective potentiality of epicatechin against oxidative stress on $\beta$ cells [106]. 
Pomegranate (Punica granatum) fruit contains flavonoids such as flavonols, anthocyanins, ellagitannins, gallotannins, and proanthocyanidins. Pomegranate has been reported to provide a beneficial effect in T2DM by decreasing the lipid peroxidation and oxidative stress by increasing some of the enzymes' antioxidant activity, decreasing the ROS, and preventing or activating PPAR $\gamma$ and NF- $\kappa \mathrm{B}$ [107].

Anthocyanins can alter tissue PPAR activity, which further affects metabolism and inflammation. In the Zucker fatty rat model of obesity and metabolic syndrome, the effect of whole tart cherry powder (prepared from anthocyanin-rich tart cherries) was evaluated after 90 days' treatment. The intake of tart cherry reduced retroperitoneal IL- 6 and TNF- $\alpha$ mRNA expression, NF- $\kappa$ B activity, and plasma IL- 6 and TNF$\alpha$ levels, and it increased retroperitoneal PPAR $\alpha$ and PPAR $\gamma$ mRNA expression. As a whole, tart cherry consumption reduced both systemic and local inflammation and metabolic syndrome, which may reduce the risk of T2DM development [108].

Macrophage infiltration in adipose tissue due to increased adiposity can lead to T2DM. In an in vitro model of inflammation in which the pathologic relationships between adipocytes and macrophages were mimicked, anthocyaninenriched fractions from blackberry-blueberry beverages were found to inhibit the secretion of NO and TNF- $\alpha$ and the phosphorylation of NF- $\kappa \mathrm{B}$ p 65 in LPS-induced macrophages [109].

T2DM is associated with chronic, low-grade, systemic inflammation accompanied by an increased production of adipokines or cytokines by obese adipose tissue. The treatment of diabetic $\mathrm{db} / \mathrm{db}$ mice with grapefruit $(0.5 \mathrm{~g} / \mathrm{kg})$ for six weeks produced antihyperglycemic effects that were accompanied by the reduced mRNA expression of proinflammatory genes such as COX-2, monocyte chemotactic protein-1, TNF$\alpha$, and $\mathrm{NF}-\kappa \mathrm{B}$ in the liver and epididymal adipose tissue. Hypermethylation at the CpG3 site of TNF $\alpha$ in adipose tissue was also found, which may contribute to a reduction of the inflammation associated with T2DM [110].

In pancreas, liver, and adipose tissue, endoplasmic reticulum (ER) stress is an early event linked to T2DM pathogenesis. In the skeletal muscle of diabetic rats, $500 \mathrm{mg} / \mathrm{kg}$ of grape seed proanthocyanidin extract (GSPE) administration for 16 weeks decreased the plasma glucose levels and insulin resistance, restored the normal activities of antioxidant enzymes and ATPases, and partially alleviated severe ER stress, which suggests that GSPE could be a useful treatment strategy for T2DM [111]. A similar study on GSPE using human adipocytes (SGBS) and macrophage-like (THP-1) cells found reduced cytokine (IL-6 and MCP-1) gene expression after an inflammatory stimulus and enhanced the production of the anti-inflammatory adipokines adiponectin (APM1) and LEP, which may prevent the low-grade inflammation of T2DM [112].

Milk fat globule epidermal growth factor-8 (MFG-E8) is highly involved in the inflammatory response. In diabetic $\mathrm{db} / \mathrm{db}$ mice, the administration of grape seed procyanidin B2 (a natural complex of polyphenol polymers) provided anti-inflammatory protection in pancreatic tissues by downregulating MFG-E8 and attenuating the levels of the proinflammatory cytokines IL-1 $\beta$ and NLRP3 [113]. Because the dysfunction of pancreatic islets is one of the mainstays in T2DM pathogenesis, protecting the pancreas from inflammation may lead to potential therapeutic approaches.

4.2.2. Vegetables. There is abundant in vitro and in vivo evidence that vegetables have anti-inflammatory and antioxidant potential for DM management. In diabetic Wistar rats, the immunomodulatory effects of a mycelial submerged culture and the broth of Grifola frondosa mushrooms were explored on splenocytes and peripheral blood cells. Two weeks of intragastric administration of fermented mycelia, broth, or their combination $(1 \mathrm{~g} / \mathrm{kg} /$ day $)$ significantly decreased the 2-hour postprandial blood glucose level, the production of T-leukocyte-derived interferon gamma (IFN$\gamma$ ), monocyte-derived IL-4 and IL-6, and T-splenocytederived IL-4, and this treatment significantly enhanced macrophage-derived TNF- $\alpha$ production [114].

In STZ-induced diabetic rats, the administration of fermented carrot juice by Lactobacillus plantarum NCU116 for five weeks positively regulated the blood glucose level, hormone, and lipid metabolism, reestablished the antioxidant capacity, restored the morphology of pancreas and kidney, and upregulated the LDL receptor, cholesterol $7 \alpha$ hydroxylase (CYP7A1), GLUT4, and PPAR $\alpha$ and PPAR $\gamma$ mRNA expression [115].

Sulforaphane (SFN) is an isothiocyanate that is naturally available in widely consumed vegetables, particularly broccoli. In diabetic male C57BL/6J mice, sulforaphane $(0.5 \mathrm{mg} /$ $\mathrm{kg}$ ) treatment for four months significantly inhibited cardiac lipid accumulation and improved cardiac inflammation, oxidative stress, and fibrosis by downregulating diabetesinduced PAI-1, TNF- $\alpha$, CTGF, TGF- $\beta$, 3-NT, and $4-\mathrm{HNE}$ expression. SFN also upregulated nuclear factor (erythroidderived 2-) like factor 2 (Nrf2) and its downstream genes, NQO1 and HO-1; SFN decreased 4-HNE-LKB1 adducts and reversed the diabetes-induced inhibition of LKB1/AMPK and its downstream targets, including sirtuin 1, PGC- $1 \alpha$, phosphorylated acetyl-CoA carboxylase, and carnitine palmitoyl transferase-1. These results suggest that the SFN treatment of T2DM mice may attenuate the cardiac oxidative stressinduced inhibition of the LKB1/AMPK signaling pathway, thereby preventing T2DM-induced lipotoxicity and cardiomyopathy [116].

Onion-derived quercetin derivatives have been regarded as the most important flavonoids for improving diabetic conditions in both in vivo and in vitro models. In STZ-induced male Sprague Dawley rats, eight days of treatment with onion peel extract $(1 \%)$ significantly $(p=0.0148)$ improved glucose tolerance, liver and skeletal muscle glycogen content $(p<$ 0.0001 and $p=0.0089$, resp.), and insulin receptor $(p=$ $0.0408)$ and GLUT4 $(p=0.0346)$ expression in muscle tissues. The oxidative stress-inducing activities, such as superoxide dismutase activity, the formation of malondialdehyde, free fatty acids in the plasma, and IL-6 expression in hepatic protein, were significantly $(p=0.0393,0.0237,0.0148$, and 0.0025 , resp.) decreased [117].

Cordycepin $\left(3^{\prime}\right.$-deoxyadenosine $)$ is produced by a traditional medicinal mushroom known as Cordyceps militaris. 
Although cordycepin has been shown to exert immunological stimulation and anti-infection and anticancer activities, the molecular mechanisms of cordycepin in T2DM are unclear. In LPS-stimulated RAW 264.7 cells, cordycepin has been found to inhibit NO, suppress NF- $\kappa \mathrm{B}$ activation, and suppress the protein expression of proinflammatory mediators that further inhibit the production of proinflammatory cytokines such as IL- $1 \beta$, IL- 6 , and TNF- $\alpha$. Moreover, an increased concentration of cordycepin decreased the T2DM-regulating genes such as $11 \beta$-HSD1 and PPAR $\gamma$ as well as the expression of costimulatory molecules such as ICAM-1 and B7-1/-2 [118].

The administration of MT- $\alpha$-glucan (isolated from Grifola frondosa mushroom fruit body), in a murine T2DM model, significantly decreased the body weight, fasting plasma glucose levels, HbAlc, TG, cholesterol, FAA, NO, NO synthase, inducible NO synthase, and malondialdehyde content in the liver. MT- $\alpha$-glucan also significantly increased the serum insulin content and hepatic glycogen content, and it reduced both the glutathione levels and the superoxide dismutase and glutathione peroxidase activity. These results suggest that the hypoglycemic effects of MT- $\alpha$-glucan in T2DM mice might be connected to its protection of pancreatic $\beta$-cells accomplished by decreasing oxidative stress and NO synthesis [119].

In an in vitro study, cocoa (Theobroma cacao) extract has shown dose-dependent inhibition of $\alpha$-amylase, $\alpha$ glucosidase, and angiotensin-1-converting enzyme activities and has also shown scavenging ability for several radicals [DPPH $(16.94 \pm 1.34 \mathrm{mg} / \mathrm{mL}), \mathrm{NO}(6.98 \pm 0.886 \mathrm{mg} / \mathrm{mL}), \mathrm{OH}$ $(3.72 \pm 0.26 \mathrm{mg} / \mathrm{mL})$, and ABTS $(15.7 \pm 1.06 \mathrm{mmol} / \mathrm{TEAC} \cdot \mathrm{g})]$ [120].

4.2.3. Spices. A variety of spices also show potential for managing DM by reducing inflammation and oxidative stress. Turmeric (Curcuma longa) contains curcumin (a polyphenolic compound) as the active ingredient, which possesses broad-spectrum biological actions such as antiinflammatory, antioxidant, and antitumor activities. In the injured lungs of diabetic rats, curcumin has been found to reduce oxidative stress and inflammatory responses and inhibit prostaglandin E2 (PGE2) and NOS. Further results revealed that curcumin inhibited the activation of $N F-\kappa \mathrm{B}$, which is a key player in inflammatory responses [121]. In $\mathrm{db} / \mathrm{db}$ mice, curcumin treatment for eight weeks increased AMPK and PPAR $\gamma$ expression and diminished NF- $\kappa$ B protein levels [122]. In T1DM patients, the development of skeletal muscle atrophy is associated with chronic inflammation. According to an in vivo study on STZ-induced T1DM C57BL/6J mice, curcumin at a dose of $1500 \mathrm{mg} / \mathrm{kg} / \mathrm{day}$ for two weeks ameliorated skeletal muscle atrophy by inhibiting NF- $\kappa$ B activation, inflammatory cytokine (TNF- $\alpha$ and IL-1 $\beta$ ) concentrations, oxidative stress, and protein ubiquitination [123]. According to an in vitro study, the treatment of solid lipid curcumin particle (SLCP) formulations (10 to $50 \mu \mathrm{g} / \mathrm{mL}$ ) using LPS-stimulated RAW 264.7 cultured murine macrophages significantly decreased the LPS-induced proinflammatory mediators NO, PGE2, and IL- 6 by inhibiting the activation of NF- $\kappa \mathrm{B}$ [124]. In another study on STZinduced diabetic Wistar-NIN rats, treatment with $0.01 \%$ curcumin or $0.5 \%$ turmeric for a period of eight weeks controlled the oxidative stress and restored normal antioxidant enzyme activities [125]. Neuronal injury can be induced by hyperglycemia-mediated oxidative stress due to diabetes. Curcuminoids, which are polyphenols of turmeric, exhibited protective effects against oxidative stress in the brain of STZinduced diabetic rats by restoring the normal level of lipid peroxidation and nitrite content and endogenous antioxidant marker enzymes [126]. In an in vitro study, curcumin was found to attenuate insulin-induced oxidative stress in hepatic stellate cells by inducing the expression of glutamate-cysteine ligase, leading to the de novo synthesis of glutathione and the suppression of insulin receptor expression [127]. In an in vitro study, pretreatment with a novel curcumin analogue (B06) at $5 \mu \mathrm{M}$ significantly reduced the high glucose-induced overexpression of inflammatory cytokines in macrophages via the inhibition of $c$-Jun $\mathrm{N}$-terminal kinase/NF- $\kappa \mathrm{B}$ activation [128].

Diabetic complications occur as a result of increased ROS due to long-term hyperglycemia. Honey and ginger have been shown to exhibit antioxidant activity by scavenging ROS. In STZ-induced Sprague Dawley rats, the combined administration of honey $(2 \mathrm{~g} / \mathrm{kg}$ body weight $)$ and ginger $(60 \mathrm{mg} / \mathrm{kg}$ body weight) for three weeks significantly $(p<0.05)$ reduced the superoxide dismutase and catalase activities and the malondialdehyde levels, whereas the reduced glutathione level and the reduced glutathione/oxidized glutathione ratio were significantly elevated $(p<0.05)$ [129]. In STZ-induced diabetic rats, oral administration with the combined extract of purple waxy corn and ginger at doses of 100, 200, and $300 \mathrm{mg} / \mathrm{kg}$ body weight for 21 days improved chronic constriction at the right sciatic nerve by improving the oxidative stress status and the axon density in the lesion nerve [130]. Ginger was also found to inhibit $\alpha$-glucosidase and $\alpha$ amylase enzymes, which is useful for T2DM management, and inhibition of COX was observed, which protects against inflammation [131]. The oral administration of ginger in diabetic rats was found to exert neuroprotective effects by increasing antioxidant defense mechanisms and downregulating malondialdehyde (MDA) levels to the normal levels in brain [132]. In another similar study, ginger administered at a dose of $500 \mathrm{mg} / \mathrm{kg} /$ day revealed a protective role on diabetic brain accomplished by reducing oxidative stress, apoptosis, and inflammation in STZ-induced diabetic rats [133]. According to another in vivo study, the treatment of STZ-induced inbred male Wistar/NIN rats for one month with ginger powder $(0.5 \%, 1 \%$, and $5 \%)$ showed protective effects against diabetes by modulating antioxidant enzymes and glutathione and downregulating lipid and protein oxidation [134]. In nicotinamide and STZ-induced diabetic rats, treatment with garlic bulb, ginger rhizome, turmeric rhizome, and their mixture ( $200 \mathrm{mg} / \mathrm{kg}$ body weight) for 28 consecutive days significantly alleviated hyperglycemia and dyslipidemia, increased insulin production, enhanced GSH, and decreased lipid peroxidation [135].

In diabetic patients, diabetic encephalopathy is one of the more severe complications. In diabetic encephalopathy rats, saffron at 40 and $80 \mathrm{mg} / \mathrm{kg}$ significantly increased the body weight and serum TNF- $\alpha$ levels and decreased the 
blood glucose, glycosylated proteins, and advanced glycation end product (AGE) levels in serum. Furthermore, saffron significantly increased the glutathione content, superoxide dismutase, and catalase but remarkably decreased the cognitive deficit and serum TNF- $\alpha$, and it induced NOS activity in hippocampus tissue [136]. In STZ-induced diabetic rats with renal injury, the administration of crocin, an active constituent of saffron, significantly decreased malondialdehyde $(p<0.01)$ and xanthine oxidase $(p<0.05)$ activities and elevated glutathione $(p<0.05)$ levels, thus ameliorating renal injury [137]. Safranal is one of the components of the saffron plant. In high-fat diet (HFD) and STZ-induced T2DM rats, safranal treatment for a period of four weeks decreased the oxidative stress caused by T2DM and reduced the inflammation by reducing the TNF- $\alpha$ and IL- $1 \beta$ levels in the plasma and pancreas tissue [138].

The protective effect of onion against oxidative stress was evaluated in an in vivo study. In STZ-induced male diabetic Wistar rats, daily treatment with $1 \mathrm{~mL}$ of Allium cepa solution ( $0.4 \mathrm{~g}$ Allium cepa/rat) increased the fasting serum high density lipoprotein levels and alleviated hyperglycemia by decreasing superoxide dismutase activities [139]. Another in vivo study also investigated the protective effects of onion against oxidative stress; 12 weeks of onion intake suppressed the diabetes-induced oxidative stress more effectively in STZinduced diabetic rats [140]. In STZ-induced diabetic male Sprague Dawley rats, supplementation with onion powder $(7 \% \mathrm{w} / \mathrm{w})$ suppressed the glutathione peroxidase, glutathione reductase, and glutathione S-transferase activities from high to normal levels [141].

Mustard leaf (Brassica juncea) has been reported to strongly inhibit the formation of AGE and free radicalmediated protein damage in in vitro studies. According to an in vivo study with STZ-induced diabetic rats, the oral administration of the EtOAc fraction of mustard leaf at doses of 50 and $200 \mathrm{mg} / \mathrm{kg}$ body weight/day for 10 days reduced the serum levels of glucose and glycosylated protein as well as the superoxide and nitrite/nitrate levels, which suggests that the EtOAc fraction of mustard leaf has the capacity to attenuate damage caused by the oxidative stress involved in diabetes and its complications [142].

Sesame butter is a natural product produced by grinding sesame seeds and is thus free from any chemical or nonchemical additives. In STZ-induced male albino Wistar rats, oral treatment with sesame butter $(1.25 \mathrm{~g} / \mathrm{kg})$ for six weeks significantly decreased the blood glucose, high density lipoprotein, and malondialdehyde levels and increased the total antioxidant capacity [143]. Sesame contains sesamin, a lignan that has been found to diminish the elevation of malondialdehyde and the reduction of superoxide dismutase activity induced by diabetes after seven weeks of treatment in male diabetic rats [144].

Eugenol (EU) is an active principle of cloves (Syzygium aromaticum) that can also be found in basil and cinnamon. In an in vitro study with SHSY5Y cells under experimentally induced hyperglycemic conditions, the exposure of cells to EU $(5-10 \mu \mathrm{M})$ improved cell viability, reduced the glutathione (GSH) levels, and significantly decreased the glucose-associated oxidative stress (by diminishing ROS and peroxide levels). From the in vivo experiment on STZinduced diabetic rats, treatment with EU at a dose of $10 \mathrm{mg} / \mathrm{kg}$ body weight/day for six weeks diminished the oxidative marker levels, GSH, and total thiols and enhanced the antioxidants activities [145]. In high-fat-diet and STZinduced T2DM rats, the administration of clove bud powder $(20-40 \mathrm{~g} / \mathrm{kg})$ reduced the blood glucose level and $\alpha$ glucosidase and liver enzyme (alanine aminotransferase, aspartate aminotransferase, and alkaline phosphatase) activities and elevated the antioxidant (glutathione, ascorbic acid, superoxide dismutase, and catalase) levels [146].

Cumin (Cuminum cyminum) is widely used as a spice in many countries. In STZ-induced diabetic rats, treatment with a methanolic extract of $C$. cyminum seeds for 28 days effectively controlled the oxidative stress, inhibited AGE formation, and improved the antioxidant status in the kidney and pancreas [147].

\section{Rheumatoid Arthritis}

RA is an inflammatory, systemic autoimmune disorder with primary degenerating articular structures involving, in particular, the cartilage (movable synovial joints of knees, shoulders, and hands) and the bones (osteoarthritis and osteoporosis) as a result of pannus formation over the joint surfaces (abnormal layer of fibrovascular or granulation tissues) $[148,149]$. The symptoms include swelling, warmth, and redness of the joints with pain, morning stiffness, fatigue, and limited functioning of the joints, which can result in poor coordination of the limbs and the deterioration of the posture $[150,151]$.

RA is the most common inflammatory arthritis and affects approximately $1 \%$ of the world population, with more than 3 million new patients being diagnosed yearly [152, 153]. It has been reported that $80 \%$ of RA patients become disabled within 20 years of diagnosis, and if left untreated, approximately $20-30 \%$ of RA patients can be permanently disabled within 2-3 years of their first diagnosis $[154,155]$. In addition, women are three times more likely to be affected than men [156]. According to a 2013 report, one in every five adults $(22.7 \%)$ in the United States has been diagnosed with arthritis [157], and the number of affected individuals is projected to increase to approximately 67 million by 2030 [158]; this is going to be an alarming health issue imposing a great socioeconomic impact worldwide.

5.1. Pathogenesis. The pathogenesis of RA involves a complex interplay between genetic and environmental factors leading to autoimmune inflammatory responses against the connective and synovial tissues of the joints [3]. In addition, increased ROS levels are actively involved in RA pathogenesis (Figure 1) [159, 160]. In typical physiological conditions, different types of cytokines are actively present in synovial tissues. However, in patients with RA, immune cells including $\mathrm{T}$ cells, B cells, and macrophages penetrate the affected synovial tissues and promote the overexpression, release, and activity of proinflammatory cytokines including TNF$\alpha$, TNF-induced NF- $\kappa \mathrm{B}$, vascular endothelial growth factor (VEGF), IL-1 beta (IL-1 $\beta$ ), IL-6, IL- 8 , and IFN- $\gamma[3,161,162]$. 
In response to these proinflammatory cytokines, fibroblastlike synoviocytes (FLS) proliferate and produce large quantities of cytokines, matrix metalloproteinases (MMPs), and COX-2, which progressively degrade cartilage and lead to joint destruction (Figure 1) [163, 164].

Oxidative stress was recently shown to be involved in the degeneration of cartilage due to the deregulation of Nrf2 or NFE2L2 [165]. When Nrf2 is activated, it binds to antioxidant response elements (AREs), resulting in the increased expression of antioxidative enzyme [e.g., Heme oxygenase-1 (HO-1)] encoding genes [166, 167]. Thus, both oxidative stress and inflammatory processes are implicated in the pathogenesis of RA.

5.2. The Role of Dietary Phytochemicals. Although synthetic regimens have been used to treat patients with RA, side effects are common and unavoidable (Table 1). Researchers have found that the regular consumption of fresh fruits, vegetables, and spices rich in important phytochemicals can attenuate oxidative stress and inflammation and relieve RA. According to some cohort studies on RA, high consumption of fruits and vegetables not only is inversely correlated with disease progression but also exerts some protective effects against RA [168-170]. Here, we discuss some of the clinical (Table 2) and experimental evidence of phytochemicals being successfully used as alternative treatments against RA.

5.2.1. Fruits and Vegetables. Osteoclastogenesis (the process of destroying bone tissues by osteoclast cells) has been observed as a clinical phenomenon in patients with RA [171]. Polyphenols extracted from dried plums can inhibit osteoclastogenesis by suppressing the activity of TNF- $\alpha$ and NO synthase and downregulating the transcription factornuclear factor for activated T cells (NFATc1) [172]. Therefore, polyphenols have the potential to be used in RA treatment.

Anthocyanins from cherry can reduce both oxidative stress (increase superoxide dismutase and decrease serum malondialdehyde) and inflammatory mediators (decrease in TNF- $\alpha$ levels) in an adjuvant-induced RA rat model (male Sprague Dawley) [173].

In 2015, resveratrol polyphenol found in red grape skin was reported to confer a significant protective effect against an aggressive RA rat model [174]. In the experiment, the activity of specific rheumatoid biomarkers [serum rheumatoid factor (RF), MMP-3 and cartilage oligomeric matrix protein (COMP)], immunological biomarkers [IgG and antinuclear antibody (ANA)], immunomodulatory cytokines (TNF- $\alpha$ ), and oxidative stress biomarkers [myeloperoxidase (MPO), CRP, and MDA] were significantly reduced by the antiinflammatory and antioxidative activities of resveratrol.

In an in vivo study with RA-induced DBA-1/J male mice, mangiferin (a natural polyphenol found especially in mangoes) suppressed the expression of IL- $1 \beta$, IL- 6 , TNF- $\alpha$, and receptor activator of NF- $\kappa \mathrm{B}$ ligand (RANKL) via the activation of extracellular signal-regulated kinase 1/2 (ERK1/2) and the inhibition of NF- $\kappa \mathrm{B}$ [175]. Another study with mangiferin demonstrated protection against joint destruction in RA by exerting strong proapoptotic effects on human synoviaderived synoviocytes [176].
Recently, Natarajan et al. [177] showed the suitability of using intra-articular injections with polyphenols to protect against cartilage degradation in collagen-induced arthritic rats. They injected a combination of different polyphenols (EGC, gallate, catechin, tannic acid, and quercetin) in RAinduced rats and observed significant $(p<0.05)$ protection effect against cartilage degradation along with attenuated inflammation.

Kaempferol (found especially in grapefruits) was shown to inhibit synovial fibroblast proliferation by suppressing inflammatory cytokines (inhibiting IL-1 $\beta$ ), inhibiting the phosphorylation of ERK-1/2, p38, and JNK, inhibiting the activation of $\mathrm{NF}-\kappa \mathrm{B}$, and reducing oxidative stress by inhibiting the production of MMPs, COX-2, and PGE2 in RAderived synovial fibroblasts [178]. All of these cytokines, transcription factors, cell signaling pathways, and enzymes are established compounds in the pathogenesis of RA that in combination destroy the articular bone and cartilage in patients with RA $[179,180]$.

An in vivo study on $p$-coumaric acid (a polyphenol present in grapes, apples, oranges, spinach, tomatoes, potatoes, wheat, oats, and maize) confirmed its potent immunosuppressive activity because it significantly $(p<0.05)$ reduced the expression of TNF- $\alpha$ in adjuvant-induced arthritic rats [181]. In a collagen-induced RA rat model (female Sprague Dawley), genistein (a polyphenol rich in soybeans) exerted anti-inflammatory activities; it maintained a balance between the Thelper cell-1 (Th1) and Th2 cells by significantly suppressing IFN- $\gamma$ and augmenting the production of IL- 4 [182].

Pattison et al. [183] reported that the modest intake of beta-cryptoxanthin (a natural carotenoid) via the daily consumption of a glass of freshly squeezed orange juice is inversely correlated with the risk of RA in humans. Additionally, arterial dysfunction is a common clinical manifestation in patients with RA that leads to cardiovascular complications $[184,185]$. Nevertheless, daily vegetable consumption was significantly $(p=0.002)$ associated with more favorable arterial function in patients with RA [186].

5.2.2. Spices. An in vivo study [187] revealed the beneficial effects of using a mixture of blended ginger, which is rich in pungent phenolic compounds (e.g., shogaols and gingerols), and turmeric, which is rich in phenolic curcuminoids (including curcumin, bisdemethoxycurcumin, and demethoxycurcumin), against extra-articular complications of RA including hematological, metabolic, and cardiovascular complications in adjuvant-induced arthritic rats (male Wistar albino). Earlier, the same group of researchers confirmed that both ginger and turmeric could independently and significantly $(p<0.05)$ protect against RA in adjuvantinduced arthritic male Wistar albino rats [188].

Cinnamon bark (Cinnamomum zeylanicum), one of the most common spices used in Indian, Bangladeshi, Burmese, and Sri Lankan dishes, can confer some protective effects against RA. Rathi et al. [189] observed a significantly $(p<$ 0.001 ) higher level of anti-inflammatory activities [inhibition of cytokines (IL-2, IL-4, and IFN- $\gamma$ ) and reduction of TNF$\alpha$ concentration] upon the treatment of RA animal models 
(male Wistar rat and Swiss albino mice) with the polyphenolic fractions of cinnamon bark.

An in vitro study with FLS (derived from RA patients) demonstrated that curcumin is a potent anti-inflammatory spice [190] that blocks the expression of IL- $1 \beta$ and IL- 6 , which are believed to play crucial roles in RA pathogenesis [191]. Elevated apoptosis within the joint is therapeutically useful [192], and curcumin has been found to increase the levels of apoptosis in rheumatic FLS [190].

Methotrexate is an antirheumatic drug widely used to treat patients with RA [193]. Vascular endothelial dysfunction has been reported as one of its most deleterious side effects due to its ability to increase oxidative stress and decrease NO levels [194]. The coadministration of curcumin with folic acid was found to abrogate methotrexate-induced vascular endothelial dysfunctions in male Wistar rats due to the attenuation of oxidative stress and the regulation of $\mathrm{NO}$ production [195].

Another recent in vivo study on male Sprague Dawley rats [196] revealed that the administration of curcumin could decrease the expression of NF- $\kappa \mathrm{B}$, TNF- $\alpha$, and IL$1 \beta$ in both synovial fluid and blood serum, thus producing effects similar to a standard antirheumatic regimen with methotrexate. Therefore, it is anticipated that curcumin could be given as antirheumatic therapy for patients with RA either administered alone or as an adjuvant with modern therapies.

5.2.3. Miscellaneous. Extra virgin olive oil (EVOO) is consumed all over the world, especially in the Mediterranean countries [197]. In 2014 [198], a group of Spanish researchers observed that polyphenolic extracts of EVOO are potent antiinflammatory substances protecting against RA-associated inflammation. An in vivo experiment conducted with a group $(n=10)$ of collagen-induced RA mice (male DBA-1/J) confirmed that polyphenolic extracts of EVOO inhibit JNK (associated with the regulation of cytokine function, T-cell differentiation, and apoptosis), p38 [involved in mitogen-activated protein kinase (MAPK) pathway, regulating cytokines and apoptosis], and signal transducer and activator of transcription-3 (STAT-3) and decrease the translocation of NF- $\kappa \mathrm{B}$. Interestingly, the activation of JNK, p38, and NF- $\kappa$ B and the overexpression of STAT-3 actively contribute to the pathogenesis of RA $[180,199,200]$. Therefore, EVOO is a potential natural source of polyphenols that can combat RA.

A recent experiment in 2015 [201] with a green teaderived polyphenolic compound called epigallocatechin-3gallate (EGCG) demonstrated that EGCG significantly $(p<$ $0.01)$ upregulates the expression of the Nrf-2 antioxidant pathway in mice (male DBA-1/J) with RA. Yoon et al. [202] observed in FLS that gallic acid (a polyphenol found in grapes, tea, gall nuts, sumac, and wine) reduced the expression levels of proinflammatory cytokines (IL- $1 \beta$ and IL-6) and enzymes, including MMP-9 and COX-2, which are involved in the inflammation and oxidation-induced pathogenesis of RA. However, the black tea-derived polyphenol theaflavin$3,3^{\prime}$-digallate (TFDG) demonstrated some protective activity against osteoclast formation and osteoporosis via the inhibition of MMP-2 and MMP-9, both of which are responsible for the degradation of collagens and joint destruction in RA patients [203, 204].

An in vivo study with cocoa-extracted polyphenols reported the suppression of TNF- $\alpha$-induced VEGF expression (involved in RA) via the inhibition of phosphoinositide 3-kinase (PI3 K) and MAPK kinase-1 (MAP2K1) activities. Grape polyphenolic extracts have been confirmed to have potent anti-inflammatory activity against RA-mediated inflammation by attenuating the expression of TNF- $\alpha$, IL1 $\beta$, IL- 6 , and IFN- $\gamma$, and they can reduce the "arthritis score" in experimental rats [205].

In LPS-stimulated macrophages, the secretion of IL-6 (found at elevated levels in patients with RA) was significantly reduced (by at least 25\%) upon incubation with polyphenolrich extracts of rooibos tea, black pepper, ginger, allspice, caraway, bay leaves, cinnamon, licorice, paprika, clove, nutmeg, and apples [206]. In addition, decreased TNF- $\alpha$ secretion (by at least $25 \%$ ) was observed upon incubation with chili pepper, black pepper, cinnamon, bay leaf, caraway, licorice, nutmeg, and bilberry extracts containing high concentrations of polyphenols [206].

\section{Conclusion}

Dietary phytochemicals are some of the most potential natural sources for developing novel drugs with improved efficiency, efficacy, and safety. Well-designed clinical trials are warranted to address the safety issues and the concurrent utility of synthetic drugs and natural compounds in attenuating oxidative stress and inflammation-mediated degenerative diseases such as RA, DM, and CVD. In in vitro and in vivo or ex vivo experiments, more emphasis should be given to studies with active compounds extracted from natural mixtures of phytochemicals. In addition, it would be interesting to conduct computational in silico analyses to determine compatible phytochemicals targeting the active sites of regulatory proteins associated with CVDs, DM, and RA to promote the development of safer and more effective drugs.

\section{Appendix}

\section{Search Strategy}

To find appropriate literature, the following terms were used in combination with Boolean operators (AND and OR).

Search \#1 (Fruits). (apple OR apricot OR applesauce OR avocado OR banana OR blackberries OR blueberries OR cantaloupe OR cherries OR dates OR dried fruits OR figs OR fruits OR fruit cocktail OR grapefruits OR grapes OR honeydew OR melon OR kiwi OR mango OR oranges OR papaya OR peaches OR pears OR pineapple OR plum OR raspberries OR strawberries OR watermelon).

Search \#2 (Vegetables). (amaranth OR Chinese spinach OR artichoke OR artichoke hearts OR asparagus OR baby corn OR bamboo shoots OR bean sprouts OR beets OR Brussels sprouts OR Broccoli OR green cabbage OR Chinese cabbage 
OR bok choy cabbage OR Italian beans OR green beans OR wax beans OR bean OR cabbage OR carrot OR cauliflower OR celery OR cucumber OR chayote OR daikon OR eggplant OR garlic OR ginger OR hearts of palm OR jicama OR kohlrabi OR leeks OR mushrooms OR onion OR okra OR pea pods OR peppers OR radish OR pepper OR black pepper OR red chills OR green chili OR rutabaga OR chicory OR escarole OR endive OR lettuce OR romaine OR arugula OR tomatoes OR Swiss chard OR spinach OR watercress OR turnip OR mustard OR collard OR sprouts OR radicchio OR peas OR turnips OR vegetables OR yard-long beans).

Search \#3 (Spices). (adobo seasoning OR allspice OR anise seed OR apple pie spice OR bay leaf OR cardamom seed OR cayenne OR chili peppers OR cinnamon OR cloves OR cumin OR curry powder OR fennel seed OR fenugreek seed OR five spice OR garam masala OR garlic OR ginger OR herb seasoning OR mace OR mustard OR nutmeg OR onion OR paprika OR peppercorns OR saffron OR sesame OR spice OR star anise OR thyme leaf OR turmeric).

Search \#4 (Phytochemicals). (antioxidants OR polyphenols OR carotenoids OR anthocyanins OR alkaloids OR glycosides OR saponins OR terpenes).

Search \#5. (Search \#1 OR Search \#2 OR Search \#3 OR Search \#4).

Search \#6 (Degenerative Diseases and Factors). Cardiovascular diseases OR diabetes OR rheumatoid arthritis OR inflammation OR proinflammatory markers OR inflammatory OR oxidative stress OR reactive oxygen species.

Search \#7. (Search \#5) AND (Search \#6).

\section{Competing Interests}

The authors declare that there are no competing interests.

\section{Authors' Contributions}

Md. Asiful Islam and Fahmida Alam are equal contributors.

\section{Acknowledgments}

The authors would like to acknowledge the Universiti Sains Malaysia (USM) Vice-Chancellor Award (2015/2016) and the USM Global Fellowship (2014/2015) awarded to Md. Asiful Islam and Fahmida Alam, respectively, to pursue their Ph.D. degrees.

\section{References}

[1] T. F. Lüscher, "Ageing, inflammation, and oxidative stress: final common pathways of cardiovascular disease," European Heart Journal, vol. 36, no. 48, pp. 3381-3383, 2015.

[2] A. O. Odegaard, D. R. Jacobs, O. A. Sanchez, D. C. Goff, A. P. Reiner, and M. D. Gross, "Oxidative stress, inflammation, endothelial dysfunction and incidence of type 2 diabetes," Cardiovascular Diabetology, vol. 15, no. 1, pp. 1-12, 2016.

[3] I. B. McInnes and G. Schett, "The pathogenesis of rheumatoid arthritis," The New England Journal of Medicine, vol. 365, no. 23, pp. 2205-2219, 2011.

[4] D. Mozaffarian, E. J. Benjamin, A. S. Go et al., "Executive summary: heart disease and stroke statistics-2016 update: a report from the American Heart Association," Circulation, vol. 133, no. 4, pp. 447-454, 2016.

[5] J. W. Beulens, D. E. Grobbee, and B. Nealb, "The global burden of diabetes and its complications: an emerging pandemic," European Journal of Cardiovascular Prevention \& Rehabilitation, vol. 17, no. 1, supplement, pp. s3-s8, 2010.

[6] B. C. Wang, P. Hsu, W. Furnback et al., "Estimating the economic burden of rheumatoid arthritis in Taiwan using the national health insurance database," Drugs-Real World Outcomes, vol. 3, no. 1, pp. 107-114, 2016.

[7] P. Alagona and T. A. Ahmad, "Cardiovascular disease risk assessment and prevention: current guidelines and limitations," Medical Clinics of North America, vol. 99, no. 4, pp. 711-731, 2015.

[8] G. R. Kokil, R. N. Veedu, G. A. Ramm, J. B. Prins, and H. S. Parekh, "Type 2 diabetes mellitus: limitations of conventional therapies and intervention with nucleic acid-based therapeutics," Chemical Reviews, vol. 115, no. 11, pp. 4719-4743, 2015.

[9] K. Albrecht and U. Müller-Ladner, "Side effects and management of side effects of methotrexate in rheumatoid arthritis," Clinical and Experimental Rheumatology, vol. 28, no. 5, supplement 61, pp. S95-S101, 2010.

[10] R. Fischer and O. Maier, "Interrelation of oxidative stress and inflammation in neurodegenerative disease: role of TNF," Oxidative Medicine and Cellular Longevity, vol. 2015, Article ID 610813, 18 pages, 2015.

[11] B. Uttara, A. V. Singh, P. Zamboni, and R. T. Mahajan, "Oxidative stress and neurodegenerative diseases: a review of upstream and downstream antioxidant therapeutic options," Current Neuropharmacology, vol. 7, no. 1, pp. 65-74, 2009.

[12] B. B. Aggarwal, S. Krishnan, and S. Guha, Inflammation, Lifestyle and Chronic Diseases: The Silent Link, CRC Press, New York, NY, USA, 2011.

[13] E. Ignatowicz and W. Baer-Dubowska, "Resveratrol, a natural chemopreventive agent against degenerative diseases," Polish Journal of Pharmacology and Pharmacy, vol. 53, no. 6, pp. 557569, 2001.

[14] S. Ojha, A. Kurdi, B. Sadek et al., "Phytochemicals as prototypes for pharmaceutical leads towards drug development against diabetic cardiomyopathy," Current Pharmaceutical Design, vol. 22, no. 20, pp. 3058-3070, 2016.

[15] M. A. Islam, F. Alam, M. I. Khalil, T. H. Sasongko, and S. H. Gan, "Natural products towards the discovery of potential future antithrombotic drugs," Current Pharmaceutical Design, vol. 22, no. 20, pp. 2926-2946, 2016.

[16] F. Alam, M. A. Islam, S. H. Gan, and M. I. Khalil, "Honey: a potential therapeutic agent for managing diabetic wounds," Evidence-Based Complementary and Alternative Medicine, vol. 2014, Article ID 169130, 16 pages, 2014.

[17] M. A. Winkleby, D. E. Jatulis, E. Frank, and S. P. Fortmann, "Socioeconomic status and health: how education, income, and occupation contribute to risk factors for cardiovascular disease," American Journal of Public Health, vol. 82, no. 6, pp. 816-820, 1992. 
[18] P. W. Franks, R. L. Hanson, W. C. Knowler, M. L. Sievers, P. H. Bennett, and H. C. Looker, "Childhood obesity, other cardiovascular risk factors, and premature death," The New England Journal of Medicine, vol. 362, no. 6, pp. 485-493, 2010.

[19] World Health Organization, "Atlas of heart disease and stroke. 2015," 2015, http://www.who.int/cardiovascular_diseases/resources/atlas/en/.

[20] R. B. Singh, S. A. Mengi, Y.-J. Xu, A. S. Arneja, and N. S. Dhalla, "Pathogenesis of atherosclerosis: a multifactorial process," Experimental and Clinical Cardiology, vol. 7, no. 1, pp. 4053, 2002.

[21] D. Wood, "Established and emerging cardiovascular risk factors," American Heart Journal, vol. 141, supplement 2, pp. S49S57, 2001.

[22] N. V. Goncharov, P. V. Avdonin, A. D. Nadeev, I. L. Zharkikh, and R. O. Jenkins, "Reactive oxygen species in pathogenesis of atherosclerosis," Current Pharmaceutical Design, vol. 21, no. 9, pp. 1134-1146, 2015.

[23] K. S. McCully, "Homocysteine and the pathogenesis of atherosclerosis," Expert Review of Clinical Pharmacology, vol. 8, no. 2, pp. 211-219, 2015.

[24] R. A. Hegele, "The genetic basis of atherosclerosis," International Journal of Clinical and Laboratory Research, vol. 27, no. 1, pp. 213, 1997.

[25] C. S. Booker and J. I. Mann, "Trans fatty acids and cardiovascular health: translation of the evidence base," Nutrition, Metabolism and Cardiovascular Diseases, vol. 18, no. 6, pp. 448456, 2008.

[26] C. Chrysohoou, D. B. Panagiotakos, C. Pitsavos et al., "The associations between smoking, physical activity, dietary habits and plasma homocysteine levels in cardiovascular disease-free people: the 'ATTICA' study,' Vascular Medicine, vol. 9, no. 2, pp. 117-123, 2004.

[27] R. Takachi, M. Inoue, J. Ishihara et al., "Fruit and vegetable intake and risk of total cancer and cardiovascular disease Japan Public Health Center-based Prospective study," American Journal of Epidemiology, vol. 167, no. 1, pp. 59-70, 2008.

[28] X. Wang, Y. Ouyang, J. Liu et al., "Fruit and vegetable consumption and mortality from all causes, cardiovascular disease, and cancer: systematic review and dose-response meta-analysis of prospective cohort studies," British Medical Journal, vol. 349, Article ID g4490, pp. 1-14, 2014.

[29] X. Gao, O. I. Bermudez, and K. L. Tucker, "Plasma C-reactive protein and homocysteine concentrations are related to frequent fruit and vegetable intake in Hispanic and non-Hispanic white elders," Journal of Nutrition, vol. 134, no. 4, pp. 913-918, 2004.

[30] H. Du, L. Li, D. Bennett et al., "Fresh fruit consumption and major cardiovascular disease in China," The New England Journal of Medicine, vol. 374, no. 14, pp. 1332-1343, 2016.

[31] P. van't Veer, M. C. Jansen, M. Klerk, and F. J. Kok, "Fruits and vegetables in the prevention of cancer and cardiovascular disease," Public Health Nutrition, vol. 3, no. 1, pp. 103-107, 2000.

[32] Y. Nagasako-Akazome, T. Kanda, Y. Ohtake, H. Shimasaki, and T. Kobayashi, "Apple polyphenols influence cholesterol metabolism in healthy subjects with relatively high body mass index," Journal of Oleo Science, vol. 56, no. 8, pp. 417-428, 2007.

[33] X. Yin, J. Quan, and T. Kanazawa, "Banana prevents plasma oxidative stress in healthy individuals," Plant Foods for Human Nutrition, vol. 63, no. 2, pp. 71-76, 2008.
[34] A. Basu, M. Du, M. J. Leyva et al., "Blueberries decrease cardiovascular risk factors in obese men and women with metabolic syndrome," The Journal of Nutrition, vol. 140, no. 9, pp. 1582-1587, 2010.

[35] A. Basu, M. Rhone, and T. J. Lyons, "Berries: emerging impact on cardiovascular health," Nutrition Reviews, vol. 68, no. 3, pp. 168-177, 2010.

[36] I. Erlund, R. Koli, G. Alfthan et al., "Favorable effects of berry consumption on platelet function, blood pressure, and HDL cholesterol," The American Journal of Clinical Nutrition, vol. 87, no. 2, pp. 323-331, 2008.

[37] J. Y. Toh, V. M. H. Tan, P. C. Y. Lim, S. T. Lim, and M. F. F. Chong, "Flavonoids from fruit and vegetables: a focus on cardiovascular risk factors," Current Atherosclerosis Reports, vol. 15, no. 12, article 368, pp. 1-7, 2013.

[38] C. Morand, C. Dubray, D. Milenkovic et al., "Hesperidin contributes to the vascular protective effects of orange juice: a randomized crossover study in healthy volunteers," American Journal of Clinical Nutrition, vol. 93, no. 1, pp. 73-80, 2011.

[39] S. Rizza, R. Muniyappa, M. Iantorno et al., "Citrus polyphenol hesperidin stimulates production of nitric oxide in endothelial cells while improving endothelial function and reducing inflammatory markers in patients with metabolic syndrome," The Journal of Clinical Endocrinology \& Metabolism, vol. 96, no. 5, pp. E782-E792, 2011.

[40] S. Gorinstein, A. Caspi, I. Libman et al., "Red grapefruit positively influences serum triglyceride level in patients suffering from coronary atherosclerosis: studies in vitro and in humans," Journal of Agricultural and Food Chemistry, vol. 54, no. 5, pp. 1887-1892, 2006.

[41] T. Ismail, P. Sestili, and S. Akhtar, "Pomegranate peel and fruit extracts: a review of potential anti-inflammatory and antiinfective effects," Journal of Ethnopharmacology, vol. 143, no. 2, pp. 397-405, 2012.

[42] C. B. Stowe, "The effects of pomegranate juice consumption on blood pressure and cardiovascular health," Complementary Therapies in Clinical Practice, vol. 17, no. 2, pp. 113-115, 2011.

[43] G. Noratto, H. S. D. Martino, S. Simbo, D. Byrne, and S. U. Mertens-Talcott, "Consumption of polyphenol-rich peach and plum juice prevents risk factors for obesity-related metabolic disorders and cardiovascular disease in Zucker rats," Journal of Nutritional Biochemistry, vol. 26, no. 6, pp. 633-641, 2015.

[44] M. Y. Hong, N. Hartig, K. Kaufman, S. Hooshmand, A. Figueroa, and M. Kern, "Watermelon consumption improves inflammation and antioxidant capacity in rats fed an atherogenic diet," Nutrition Research, vol. 35, no. 3, pp. 251-258, 2015.

[45] T. C. Wallace, "Anthocyanins in cardiovascular disease," Advances in Nutrition, vol. 2, no. 1, pp. 1-7, 2011.

[46] M. A. Vazquez-Prieto and R. M. Miatello, "Organosulfur compounds and cardiovascular disease," Molecular Aspects of Medicine, vol. 31, no. 6, pp. 540-545, 2010.

[47] H. S. Chang, O. Yamato, M. Yamasaki, and Y. Maede, "Modulatory influence of sodium 2-propenyl thiosulfate from garlic on cyclooxygenase activity in canine platelets: possible mechanism for the anti-aggregatory effect," Prostaglandins Leukotrienes and Essential Fatty Acids, vol. 72, no. 5, pp. 351-355, 2005.

[48] J. Terao, Y. Kawai, and K. Murota, "Vegetable flavonoids and cardiovascular disease," Asia Pacific Journal of Clinical Nutrition, vol. 17, supplement 1, pp. 291-293, 2008.

[49] C. P. Bondonno, X. Yang, K. D. Croft et al., "Flavonoid-rich apples and nitrate-rich spinach augment nitric oxide status and 
improve endothelial function in healthy men and women: a randomized controlled trial," Free Radical Biology \& Medicine, vol. 52, no. 1, pp. 95-102, 2012.

[50] S. Auclair, G. Chironi, D. Milenkovic et al., "The regular consumption of a polyphenol-rich apple does not influence endothelial function: a randomised double-blind trial in hypercholesterolemic adults," European Journal of Clinical Nutrition, vol. 64, no. 10, pp. 1158-1165, 2010.

[51] P. Valderas-Martinez, G. Chiva-Blanch, R. Casas et al., "Tomato sauce enriched with olive oil exerts greater effects on cardiovascular disease risk factors than raw tomato and tomato sauce: a randomized trial," Nutrients, vol. 8, no. 3, article 170, 2016.

[52] F. Squadrito, D. Altavilla, A. Crisafulli et al., "Effect of genistein on endothelial function in postmenopausal women: a randomized, double-blind, controlled study," The American Journal of Medicine, vol. 114, no. 6, pp. 470-476, 2003.

[53] S. Egert, A. Bosy-Westphal, J. Seiberl et al., "Quercetin reduces systolic blood pressure and plasma oxidised low-density lipoprotein concentrations in overweight subjects with a high-cardiovascular disease risk phenotype: a double-blinded, placebo-controlled cross-over study," British Journal of Nutrition, vol. 102, no. 7, pp. 1065-1074, 2009.

[54] S. S. Hassellund, A. Flaa, S. E. Kjeldsen et al., "Effects of anthocyanins on cardiovascular risk factors and inflammation in pre-hypertensive men: a double-blind randomized placebocontrolled crossover study," Journal of Human Hypertension, vol. 27, no. 2, pp. 100-106, 2013.

[55] S. Kianbakht, B. Abasi, and F. Hashem Dabaghian, "Improved lipid profile in hyperlipidemic patients taking Vaccinium arctostaphylos fruit hydroalcoholic extract: a randomized doubleblind placebo-controlled clinical trial," Phytotherapy Research, vol. 28, no. 3, pp. 432-436, 2014.

[56] R. Soltani, M. Hakimi, S. Asgary, S. M. Ghanadian, M. Keshvari, and N. Sarrafzadegan, "Evaluation of the effects of Vaccinium arctostaphylos L. fruit extract on serum lipids and hs-CRP levels and oxidative stress in adult patients with hyperlipidemia: a randomized, double-blind, placebo-controlled clinical trial," Evidence-Based Complementary and Alternative Medicine, vol. 2014, Article ID 217451, 6 pages, 2014.

[57] D. Taubert, R. Roesen, C. Lehmann, N. Jung, and E. Schömig, "Effects of low habitual cocoa intake on blood pressure and bioactive nitric oxide: a randomized controlled trial," The Journal of the American Medical Association, vol. 298, no. 1, pp. 49-60, 2007.

[58] Z. Faridi, V. Y. Njike, S. Dutta, A. Ali, and D. L. Katz, "Acute dark chocolate and cocoa ingestion and endothelial function: a randomized controlled crossover trial," The American Journal of Clinical Nutrition, vol. 88, no. 1, pp. 58-63, 2008.

[59] N. M. K. Selvi, M. G. Sridhar, R. P. Swaminathan, and R. Sripradha, "Efficacy of turmeric as adjuvant therapy in type 2 diabetic patients," Indian Journal of Clinical Biochemistry, vol. 30, no. 2, pp. 180-186, 2015.

[60] T. Arablou, N. Aryaeian, M. Valizadeh, F. Sharifi, A. Hosseini, and M. Djalali, "The effect of ginger consumption on glycemic status, lipid profile and some inflammatory markers in patients with type 2 diabetes mellitus," International Journal of Food Sciences and Nutrition, vol. 65, no. 4, pp. 515-520, 2014.

[61] J. Tomé-Carneiro, M. Larrosa, M. J. Yáñez-Gascón et al., “Oneyear supplementation with a grape extract containing resveratrol modulates inflammatory-related microRNAs and cytokines expression in peripheral blood mononuclear cells of type 2 diabetes and hypertensive patients with coronary artery disease," Pharmacological Research, vol. 72, pp. 69-82, 2013.

[62] S. Moazen, R. Amani, A. Homayouni Rad, H. Shahbazian, K. Ahmadi, and M. Taha Jalali, "Effects of freeze-dried strawberry supplementation on metabolic biomarkers of atherosclerosis in subjects with type 2 diabetes: a randomized double-blind controlled trial," Annals of Nutrition and Metabolism, vol. 63, no. 3, pp. 256-264, 2013.

[63] S. Mahluji, A. Ostadrahimi, M. Mobasseri, V. E. Attari, and L. Payahoo, "Anti-inflammatory effects of Zingiber officinale in type 2 diabetic patients," Advanced Pharmaceutical Bulletin, vol. 3, no. 2, pp. 273-276, 2013.

[64] Z. Bahadoran, P. Mirmiran, F. Hosseinpanah, M. Hedayati, S. Hosseinpour-Niazi, and F. Azizi, "Broccoli sprouts reduce oxidative stress in type 2 diabetes: a randomized double-blind clinical trial," European Journal of Clinical Nutrition, vol. 65, no. 8, pp. 972-977, 2011.

[65] P. Kar, D. Laight, H. K. Rooprai, K. M. Shaw, and M. Cummings, "Effects of grape seed extract in Type 2 diabetic subjects at high cardiovascular risk: a double blind randomized placebo controlled trial examining metabolic markers, vascular tone, inflammation, oxidative stress and insulin sensitivity," Diabetic Medicine, vol. 26, no. 5, pp. 526-531, 2009.

[66] B. Chandran and A. Goel, "A randomized, pilot study to assess the efficacy and safety of curcumin in patients with active rheumatoid arthritis," Phytotherapy Research, vol. 26, no. 11, pp. 1719-1725, 2012.

[67] S.-C. Bae, W.-J. Jung, E.-J. Lee, R. Yu, and M.-K. Sung, "Effects of antioxidant supplements intervention on the level of plasma inflammatory molecules and disease severity of rheumatoid arthritis patients," Journal of the American College of Nutrition, vol. 28, no. 1, pp. 56-62, 2009.

[68] C. M. Bitler, K. Matt, M. Irving et al., "Olive extract supplement decreases pain and improves daily activities in adults with osteoarthritis and decreases plasma homocysteine in those with rheumatoid arthritis," Nutrition Research, vol. 27, no. 8, pp. 470477, 2007.

[69] A. Upaganlawar, V. Patel, and R. Balaraman, "Tomato lycopene attenuates myocardial infarction induced by isoproterenol: electrocardiographic, biochemical and anti-apoptotic study," Asian Pacific Journal of Tropical Biomedicine, vol. 2, no. 5, pp. 345-351, 2012.

[70] B. L. B. Pereira, F. C. O. Arruda, P. P. Reis et al., "Tomato (Lycopersicon esculentum) supplementation induces changes in cardiac miRNA expression, reduces oxidative stress and left ventricular mass, and improves diastolic function," Nutrients, vol. 7, no. 11, pp. 9640-9649, 2015.

[71] H. D. Sesso, S. Liu, J. M. Gaziano, and J. E. Buring, "Dietary lycopene, tomato-based food products and cardiovascular disease in women," Journal of Nutrition, vol. 133, no. 7, pp. 23362341, 2003

[72] R. Grzanna, L. Lindmark, and C. G. Frondoza, "Ginger-an herbal medicinal product with broad anti-inflammatory actions," Journal of Medicinal Food, vol. 8, no. 2, pp. 125-132, 2005.

[73] M. Thomson, K. K. Al-Qattan, S. M. Al-Sawan, M. A. Alnaqeeb, I. Khan, and M. Ali, "The use of ginger (Zingiber officinale Rosc.) as a potential anti-inflammatory and antithrombotic agent," Prostaglandins, Leukotrienes and Essential Fatty Acids, vol. 67, no. 6, pp. 475-478, 2002.

[74] R. S. Ahmed, V. Seth, and B. D. Banerjee, "Influence of dietary ginger (Zingiber officinales Rosc) on antioxidant defense system 
in rat: Comparison with ascorbic acid," Indian Journal of Experimental Biology, vol. 38, no. 6, pp. 604-606, 2000.

[75] A. Bordia, S. K. Verma, and K. C. Srivastava, "Effect of ginger (Zingiber officinale Rosc.) and fenugreek (Trigonella foenumgraecum L.) on blood lipids, blood sugar and platelet aggregation in patients with coronary artery disease," Prostaglandins Leukotrienes and Essential Fatty Acids, vol. 56, no. 5, pp. 379384, 1997.

[76] M. Kobayashi, Y. Ishida, N. Shoji, and Y. Ohizumi, "Cardiotonic action of [8]-gingerol, an activator of the $\mathrm{Ca}^{++}$-pumping adenosine triphosphatase of sarcoplasmic reticulum, in guinea pig atrial muscle," Journal of Pharmacology and Experimental Therapeutics, vol. 246, no. 2, pp. 667-673, 1988.

[77] M. N. Ghayur and A. H. Gilani, "Ginger lowers blood pressure through blockade of voltage-dependent calcium channels," Journal of Cardiovascular Pharmacology, vol. 45, no. 1, pp. 7480, 2005.

[78] B. Fuhrman, M. Rosenblat, T. Hayek, R. Coleman, and M. Aviram, "Ginger extract consumption reduces plasma cholesterol, inhibits LDL oxidation and attenuates development of atherosclerosis in atherosclerotic, apolipoprotein E-deficient mice," Journal of Nutrition, vol. 130, no. 5, pp. 1124-1131, 2000.

[79] A. S. Wakade, A. S. Shah, M. P. Kulkarni, and A. R. Juvekar, "Protective effect of Piper longum L. on oxidative stress induced injury and cellular abnormality in adriamycin induced cardiotoxicity in rats," Indian Journal of Experimental Biology, vol. 46, no. 7, pp. 528-533, 2008.

[80] R. S. Vijayakumar, D. Surya, R. Senthilkumar, and N. Nalini, "Hypolipidemic effect of black pepper (Piper nigrum Linn.) in Rats fed high fat diet," Journal of Clinical Biochemistry and Nutrition, vol. 32, pp. 31-42, 2002.

[81] S. Joukar, H. Najafipour, M. Khaksari et al., "The effect of saffron consumption on biochemical and histopathological heart indices of rats with myocardial infarction," Cardiovascular Toxicology, vol. 10, no. 1, pp. 66-71, 2010.

[82] R. Mehdizadeh, M.-R. Parizadeh, A.-R. Khooei, S. Mehri, and H. Hosseinzadeh, "Cardioprotective effect of saffron extract and safranal in isoproterenol-induced myocardial infarction in wistar rats," Iranian Journal of Basic Medical Sciences, vol. 16, no. 1, pp. 56-63, 2013.

[83] G. K. Jayaprakasha, L. J. M. Rao, and K. K. Sakariah, "Volatile constituents from Cinnamomum zeylanicum fruit stalks and their antioxidant activities," Journal of Agricultural and Food Chemistry, vol. 51, no. 15, pp. 4344-4348, 2003.

[84] Z.-M. Wang, B. Zhou, Y.-S. Wang et al., "Black and green tea consumption and the risk of coronary artery disease: a metaanalysis," The American Journal of Clinical Nutrition, vol. 93, no. 3, pp. 506-515, 2011.

[85] B. Buijsse, E. J. M. Feskens, F. J. Kok, and D. Kromhout, "Cocoa intake, blood pressure, and cardiovascular mortality: the Zutphen Elderly Study," Archives of Internal Medicine, vol. 166, no. 4, pp. 411-417, 2006.

[86] L. Hooper, C. Kay, A. Abdelhamid et al., "Effects of chocolate, cocoa, and flavan-3-ols on cardiovascular health: a systematic review and meta-analysis of randomized trials," American Journal of Clinical Nutrition, vol. 95, no. 3, pp. 740-751, 2012.

[87] R. Corti, A. J. Flammer, N. K. Hollenberg, and T. F. Lüscher, "Cocoa and cardiovascular health," Circulation, vol. 119, no. 10, pp. 1433-1441, 2009.

[88] L. Jia, X. Liu, Y. Y. Bai et al., "Short-term effect of cocoa product consumption on lipid profile: a meta-analysis of randomized controlled trials," The American Journal of Clinical Nutrition, vol. 92, no. 1, pp. 218-225, 2010.

[89] American Diabetes Association, "Diagnosis and classification of diabetes mellitus," Diabetes Care, vol. 37, supplement 1, pp. S81-S90, 2013.

[90] F. Alam, M. A. Islam, M. I. Khalil, and S. H. Gan, "Metabolic control of type 2 diabetes by targeting the GLUT4 glucose transporter: intervention approaches," Current Pharmaceutical Design, vol. 22, no. 20, pp. 3034-3049, 2016.

[91] B. B. Kahn, "Type 2 diabetes: when insulin secretion fails to compensate for insulin resistance," Cell, vol. 92, no. 5, pp. 593596, 1998.

[92] M. Y. Donath, "Targeting inflammation in the treatment of type 2 diabetes: time to start," Nature Reviews Drug Discovery, vol.13, no. 6, pp. 465-476, 2014.

[93] L. Guariguata, D. R. Whiting, I. Hambleton, J. Beagley, U. Linnenkamp, and J. E. Shaw, "Global estimates of diabetes prevalence for 2013 and projections for 2035," Diabetes Research and Clinical Practice, vol. 103, no. 2, pp. 137-149, 2014.

[94] J. C. Pickup, "Inflammation and activated innate immunity in the pathogenesis of type 2 diabetes," Diabetes Care, vol. 27, no. 3, pp. 813-823, 2004.

[95] S. E. Shoelson, J. Lee, and A. B. Goldfine, "Inflammation and insulin resistance," The Journal of Clinical Investigation, vol. 116, no. 7, pp. 1793-1801, 2006.

[96] E. D. Werner, J. Lee, L. Hansen, M. Yuan, and S. E. Shoelson, "Insulin resistance due to phosphorylation of insulin receptor substrate-1 at serine 302," The Journal of Biological Chemistry, vol. 279, no. 34, pp. 35298-35305, 2004.

[97] Y. Zick, "Ser/Thr phosphorylation of IRS proteins: a molecular basis for insulin resistance," Science Signaling, vol. 2005, no. 268, article pe 4, 2005.

[98] D. Cai, M. Yuan, D. F. Frantz et al., "Local and systemic insulin resistance resulting from hepatic activation of IKK- $\beta$ and NF$\kappa$ B," Nature Medicine, vol. 11, no. 2, pp. 183-190, 2005.

[99] U. Asmat, K. Abad, and K. Ismail, "Diabetes mellitus and oxidative stress-a concise review," Saudi Pharmaceutical Journal, 2015.

[100] M. Solayman, Y. Ali, F. Alam et al., "Polyphenols: potential future arsenals in the treatment of diabetes," Current Pharmaceutical Design, vol. 22, no. 5, pp. 549-565, 2016.

[101] D. J. Betteridge, "What is oxidative stress?" Metabolism, vol. 49, no. 2 , pp. 3-8, 2000.

[102] A. N. Murunga, D. O. Miruka, C. Driver, F. S. Nkomo, S. Z. Cobongela, and P. M. Owira, "Grapefruit derived flavonoid naringin improves ketoacidosis and lipid peroxidation in type 1 diabetes rat model," PLoS ONE, vol. 11, no. 4, Article ID e0153241, pp. 1-16, 2016.

[103] A. K. Sharma, S. Bharti, S. Ojha et al., "Up-regulation of PPAR $\gamma$, heat shock protein-27 and- 72 by naringin attenuates insulin resistance, $\beta$-cell dysfunction, hepatic steatosis and kidney damage in a rat model of type 2 diabetes," British Journal of Nutrition, vol. 106, no. 11, pp. 1713-1723, 2011.

[104] C.-C. Chang, C.-Y. Chang, J.-P. Huang, and L.-M. Hung, "Effect of resveratrol on oxidative and inflammatory stress in liver and spleen of streptozotocin-induced type 1 diabetic rats," Chinese Journal of Physiology, vol. 55, no. 3, pp. 192-201, 2012.

[105] S. Sekhon-Loodu, Ziaullah, and H. P. V. Rupasinghe, "Docosahexaenoic acid ester of phloridzin inhibit lipopolysaccharideinduced inflammation in THP-1 differentiated macrophages," International Immunopharmacology, vol. 25, no. 1, pp. 199-206, 2015. 
[106] M. Á. Martín, E. Fernández-Millán, S. Ramos, L. Bravo, and L. Goya, "Cocoa flavonoid epicatechin protects pancreatic beta cell viability and function against oxidative stress," Molecular Nutrition \& Food Research, vol. 58, no. 3, pp. 447-456, 2014.

[107] S. Banihani, S. Swedan, and Z. Alguraan, "Pomegranate and type 2 diabetes," Nutrition Research, vol. 33, no. 5, pp. 341-348, 2013.

[108] E. M. Seymour, S. K. Lewis, D. E. Urcuyo-Llanes et al., "Regular tart cherry intake alters abdominal adiposity, adipose gene transcription, and inflammation in obesity-prone rats fed a high fat diet," Journal of Medicinal Food, vol. 12, no. 5, pp. 935-942, 2009.

[109] D. F. Garcia-Diaz, M. H. Johnson, and E. G. de Mejia, "Anthocyanins from fermented berry beverages inhibit inflammationrelated adiposity response in vitro," Journal of Medicinal Food, vol. 18, no. 4, pp. 489-496, 2015.

[110] A. D. de la Garza, U. Etxeberria, S. Palacios-Ortega et al., "Modulation of hyperglycemia and TNF $\alpha$-mediated inflammation by helichrysum and grapefruit extracts in diabetic $\mathrm{db} / \mathrm{db}$ mice," Food \& Function, vol. 5, no. 9, pp. 2120-2128, 2014.

[111] Y. Ding, X. Dai, Y. Jiang et al., "Grape seed proanthocyanidin extracts alleviate oxidative stress and ER stress in skeletal muscle of low-dose streptozotocin- and high-carbohydrate/highfat diet-induced diabetic rats," Molecular Nutrition \& Food Research, vol. 57, no. 2, pp. 365-369, 2013.

[112] M. R. Chacón, V. Ceperuelo-Mallafré, E. Maymó-Masip et al., "Grape-seed procyanidins modulate inflammation on human differentiated adipocytes in vitro," Cytokine, vol. 47, no. 2, pp. 137-142, 2009.

[113] W. Yin, B. Li, X. Li et al., "Anti-inflammatory effects of grape seed procyanidin B2 on a diabetic pancreas," Food \& Function, vol. 6, no. 9, pp. 3065-3071, 2015.

[114] Y.-H. Chen, C.-H. Lee, T.-H. Hsu, and H.-C. Lo, "Submergedculture mycelia and broth of the maitake medicinal mushroom Grifola frondosa (higher basidiomycetes) alleviate type 2 diabetes-induced alterations in immunocytic function," International Journal of Medicinal Mushrooms, vol. 17, no. 6, pp. 541556, 2015.

[115] C. Li, Q. Ding, S.-P. Nie, Y.-S. Zhang, T. Xiong, and M.-Y. Xie, "Carrot juice fermented with Lactobacillus plantarum NCU116 ameliorates type 2 diabetes in rats," Journal of Agricultural and Food Chemistry, vol. 62, no. 49, pp. 11884-11891, 2014.

[116] Z. Zhang, S. Wang, S. Zhou et al., "Sulforaphane prevents the development of cardiomyopathy in type 2 diabetic mice probably by reversing oxidative stress-induced inhibition of LKB1/AMPK pathway," Journal of Molecular and Cellular Cardiology, vol. 77, pp. 42-52, 2014.

[117] J. Y. Jung, Y. Lim, M. S. Moon, J. Y. Kim, and O. Kwon, “Onion peel extracts ameliorate hyperglycemia and insulin resistance in high fat diet/streptozotocin-induced diabetic rats," Nutrition \& Metabolism, vol. 8, no. 1, article 18, pp. 1-8, 2011.

[118] S. Shin, S. Lee, J. Kwon et al., “Cordycepin suppresses expression of diabetes regulating genes by inhibition of lipopolysaccharideinduced inflammation in macrophages," Immune Network, vol. 9, no. 3, pp. 98-105, 2009.

[119] H. Lei, M. Zhang, Q. Wang et al., "MT- $\alpha$-glucan from the fruit body of the maitake medicinal mushroom Grifola frondosa (higher Basidiomyetes) shows protective effects for hypoglycemic pancreatic $\beta$-cells," International Journal of Medicinal Mushrooms, vol. 15, no. 4, pp. 373-381, 2013.
[120] G. Oboh, A. O. Ademosun, A. O. Ademiluyi, O. S. Omojokun, E. E. Nwanna, and K. O. Longe, "In vitro studies on the antioxidant property and inhibition of $\alpha$-amylase, $\alpha$-glucosidase, and angiotensin I-converting enzyme by polyphenol-rich extracts from cocoa (Theobroma cacao) Bean," Pathology Research International, vol. 2014, Article ID 549287, 6 pages, 2014.

[121] F. Zhang, F. Yang, H. Zhao, and Y. An, "Curcumin alleviates lung injury in diabetic rats by inhibiting nuclear factor- $\kappa \mathrm{B}$ pathway," Clinical and Experimental Pharmacology and Physiology, vol. 42, no. 9, pp. 956-963, 2015.

[122] L. M. Jiménez-Flores, S. López-Briones, M. H. MacíasCervantes, J. Ramírez-Emiliano, and V. Pérez-Vázquez, "A PPAR $\gamma, \mathrm{NF}-\kappa \mathrm{B}$ and AMPK-dependent mechanism may be involved in the beneficial effects of curcumin in the diabetic db/db mice liver," Molecules, vol. 19, no. 6, pp. 8289-8302, 2014.

[123] T. Ono, S. Takada, S. Kinugawa, and H. Tsutsui, "Curcumin ameliorates skeletal muscle atrophy in type 1 diabetic mice by inhibiting protein ubiquitination," Experimental Physiology, vol. 100, no. 9, pp. 1052-1063, 2015.

[124] P. P. Nahar, A. L. Slitt, and N. P. Seeram, "Anti-inflammatory effects of novel standardized solid lipid curcumin formulations," Journal of Medicinal Food, vol. 18, no. 7, pp. 786-792, 2015.

[125] P. Suryanarayana, A. Satyanarayana, N. Balakrishna, P. U. Kumar, and G. B. Reddy, "Effect of turmeric and curcumin on oxidative stress and antioxidant enzymes in streptozotocininduced diabetic rat," Medical Science Monitor, vol. 13, no. 12, pp. BR286-BR292, 2007.

[126] M. Rastogi, R. P. Ojha, G. V. Rajamanickam, A. Agrawal, A. Aggarwal, and G. P. Dubey, "Curcuminoids modulates oxidative damage and mitochondrial dysfunction in diabetic rat brain," Free Radical Research, vol. 42, no. 11-12, pp. 999-1005, 2008.

[127] J. Lin, S. Zheng, and A. Chen, "Curcumin attenuates the effects of insulin on stimulating hepatic stellate cell activation by interrupting insulin signaling and attenuating oxidative stress," Laboratory Investigation, vol. 89, no. 12, pp. 1397-1409, 2009.

[128] Y. Pan, G. Zhu, Y. Wang et al., "Attenuation of high-glucoseinduced inflammatory response by a novel curcumin derivative B06 contributes to its protection from diabetic pathogenic changes in rat kidney and heart," Journal of Nutritional Biochemistry, vol. 24, no. 1, pp. 146-155, 2013.

[129] N. F. Abdul Sani, L. K. Belani, C. Pui Sin et al., "Effect of the combination of gelam honey and ginger on oxidative stress and metabolic profile in streptozotocin-induced diabetic spraguedawley rats," BioMed Research International, vol. 2014, Article ID 160695, 9 pages, 2014.

[130] J. Wattanathorn, P. Thiraphatthanavong, S. Muchimapura, W. Thukhammee, K. Lertrat, and B. Suriharn, "The combined extract of Zingiber officinale and Zea mays (purple color) improves neuropathy, oxidative stress, and axon density in streptozotocin induced diabetic rats," Evidence-Based Complementary and Alternative Medicine, vol. 2015, Article ID 301029, 11 pages, 2015.

[131] M. Priya Rani, K. P. Padmakumari, B. Sankarikutty, O. Lijo Cherian, V. M. Nisha, and K. G. Raghu, "Inhibitory potential of ginger extracts against enzymes linked to type 2 diabetes, inflammation and induced oxidative stress," International Journal of Food Sciences and Nutrition, vol. 62, no. 2, pp. 106-110, 2011.

[132] K. R. Shanmugam, K. Mallikarjuna, N. Kesireddy, and K. S. Reddy, "Neuroprotective effect of ginger on anti-oxidant enzymes in streptozotocin-induced diabetic rats," Food and Chemical Toxicology, vol. 49, no. 4, pp. 893-897, 2011. 
[133] G. El-Akabawy and W. El-Kholy, "Neuroprotective effect of ginger in the brain of streptozotocin-induced diabetic rats," Annals of Anatomy, vol. 196, no. 2-3, pp. 119-128, 2014.

[134] N. Kota, V. V. Panpatil, R. Kaleb, B. Varanasi, and K. Polasa, "Dose-dependent effect in the inhibition of oxidative stress and anticlastogenic potential of ginger in STZ induced diabetic rats," Food Chemistry, vol. 135, no. 4, pp. 2954-2959, 2012.

[135] H. R. Madkor, S. W. Mansour, and G. Ramadan, "Modulatory effects of garlic, ginger, turmeric and their mixture on hyperglycaemia, dyslipidaemia and oxidative stress in streptozotocinnicotinamide diabetic rats," British Journal of Nutrition, vol. 105, no. 8, pp. 1210-1217, 2011.

[136] S. Samarghandian, M. Azimi-Nezhad, and F. Samini, "Ameliorative effect of saffron aqueous extract on hyperglycemia, hyperlipidemia, and oxidative stress on diabetic encephalopathy in streptozotocin induced experimental diabetes mellitus," BioMed Research International, vol. 2014, Article ID 920857, 12 pages, 2014.

[137] E. Altinoz, Z. Oner, H. Elbe, Y. Cigremis, and Y. Turkoz, "Protective effects of saffron (its active constituent, crocin) on nephropathy in streptozotocin-induced diabetic rats," Human \& Experimental Toxicology, vol. 34, no. 2, pp. 127-134, 2015.

[138] Ö. Hazman and S. Ovalı, "Investigation of the antiinflammatory effects of safranal on high-fat diet and multiple low-dose streptozotocin induced type 2 diabetes rat model," Inflammation, vol. 38, no. 3, pp. 1012-1019, 2015.

[139] K. E. Campos, Y. S. Diniz, A. C. Cataneo, L. A. Faine, M. J. Q. F. Alves, and E. L. B. Novelli, "Hypoglycaemic and antioxidant effects of onion, Allium cepa: dietary onion addition, antioxidant activity and hypoglycaemic effects on diabetic rats," International Journal of Food Sciences and Nutrition, vol. 54, no. 3, pp. 241-246, 2003.

[140] K. Azuma, Y. Minami, K. Ippoushi, and J. Terao, "Lowering effects of onion intake on oxidative stress biomarkers in streptozotocin-induced diabetic rats," Journal of Clinical Biochemistry and Nutrition, vol. 40, no. 2, pp. 131-140, 2007.

[141] M. Bang, H.-A. Kim, and Y.-J. Cho, "Alterations in the blood glucose, serum lipids and renal oxidative stress in diabetic rats by supplementation of onion (Allium cepa. Linn)," Nutrition Research and Practice, vol. 3, no. 3, pp. 242-246, 2009.

[142] T. Yokozawa, H. Y. Kim, E. J. Cho, N. Yamabe, and J. S. Choi, "Protective effects of mustard leaf (Brassica juncea) against diabetic oxidative stress," Journal of Nutritional Science and Vitaminology, vol. 49, no. 2, pp. 87-93, 2003.

[143] F. Haidari, M. Mohammadshahi, M. Zarei, and Z. Gorji, "Effects of sesame butter (Ardeh) versus sesame oil on metabolic and oxidative stress markers in streptozotocin-induced diabetic rats," Iranian Journal of Medical Sciences, vol. 41, no. 2, pp. 102109, 2016.

[144] T. Baluchnejadmojarad, M. Roghani, M.-R. Jalali Nadoushan et al., "The sesame lignan sesamin attenuates vascular dysfunction in streptozotocin diabetic rats: involvement of nitric oxide and oxidative stress," European Journal of Pharmacology, vol. 698, no. 1-3, pp. 316-321, 2013.

[145] S. N. Prasad, M. S. Bharath, and Muralidhara, "Neurorestorative effects of eugenol, a spice bioactive: evidence in cell model and its efficacy as an intervention molecule to abrogate brain oxidative dysfunctions in the streptozotocin diabetic rat," Neurochemistry International, vol. 95, pp. 24-36, 2016.

[146] S. A. Adefegha, G. Oboh, O. M. Adefegha, A. A. Boligon, and M. L. Athayde, "Antihyperglycemic, hypolipidemic, hepatoprotective and antioxidative effects of dietary clove (Szyzgium aromaticum) bud powder in a high-fat diet/streptozotocininduced diabetes rat model," Journal of the Science of Food and Agriculture, vol. 94, no. 13, pp. 2726-2737, 2014.

[147] A. G. Jagtap and P. B. Patil, "Antihyperglycemic activity and inhibition of advanced glycation end product formation by Cuminum cyminum in streptozotocin induced diabetic rats," Food and Chemical Toxicology, vol. 48, no. 8-9, pp. 2030-2036, 2010.

[148] M.-C. Boissier, L. Semerano, S. Challal, N. Saidenberg-Kermanac'h, and G. Falgarone, "Rheumatoid arthritis: from autoimmunity to synovitis and joint destruction," Journal of Autoimmunity, vol. 39, no. 3, pp. 222-228, 2012.

[149] J. S. Smolen, D. Aletaha, M. Koeller, M. H. Weisman, and P. Emery, "New therapies for treatment of rheumatoid arthritis," The Lancet, vol. 370, no. 9602, pp. 1861-1874, 2007.

[150] S. Shiozawa and K. Tsumiyama, "Pathogenesis of rheumatoid arthritis and c-Fos/AP-1," Cell Cycle, vol. 8, no. 10, pp. 1539-1543, 2009.

[151] H. B. Sun, "Mechanical loading, cartilage degradation, and arthritis," Annals of the New York Academy of Sciences, vol. 1211, no. 1, pp. 37-50, 2010.

[152] D. L. Scott, F. Wolfe, and T. W. J. Huizinga, "Rheumatoid arthritis," The Lancet, vol. 376, no. 9746, pp. 1094-1108, 2010.

[153] N. Vivar and R. F. Van Vollenhoven, "Advances in the treatment of rheumatoid arthritis," F1000Prime Reports, vol. 6, no. 31, pp. $1-9,2014$

[154] J. A. Rindfleisch and D. Muller, "Diagnosis and management of rheumatoid arthritis," American Family Physician, vol. 72, no. 6, pp. 1037-1047, 2005.

[155] G. Schmajuk, A. N. Trivedi, D. H. Solomon et al., "Receipt of disease-modifying antirheumatic drugs among patients with rheumatoid arthritis in medicare managed care plans," The Journal of the American Medical Association, vol. 305, no. 5, pp. 480-486, 2011.

[156] K. A. Theis, C. G. Helmick, and J. M. Hootman, "Arthritis burden and impact are greater among U.S. women than men: intervention opportunities," Journal of Women's Health, vol. 16, no. 4, pp. 441-453, 2007.

[157] K. E. Barbour, C. G. Helmick, K. A. Theis et al., "Prevalence of doctor-diagnosed arthritis and arthritis-attributable activity limitation-United States," Morbidity and Mortality Weekly Report, vol. 62, no. 44, pp. 869-873, 2013.

[158] J. M. Hootman and C. G. Helmick, "Projections of US prevalence of arthritis and associated activity limitations," Arthritis \& Rheumatism, vol. 54, no. 1, pp. 226-229, 2006.

[159] C. A. Hitchon and H. S. El-Gabalawy, "Oxidation in rheumatoid arthritis," Arthritis Research \& Therapy, vol. 6, no. 6, pp. 265278, 2004.

[160] J. Fay, D. Varoga, C. J. Wruck, B. Kurz, M. B. Goldring, and T. Pufe, "Reactive oxygen species induce expression of vascular endothelial growth factor in chondrocytes and human articular cartilage explants," Arthritis Research \& Therapy, vol. 8, article R189, 2006.

[161] I. B. McInnes and G. Schett, "Cytokines in the pathogenesis of rheumatoid arthritis," Nature Reviews Immunology, vol. 7, no. 6, pp. 429-442, 2007.

[162] S.-A. Yoo, S.-K. Kwok, and W.-U. Kim, "Proinflammatory role of vascular endothelial growth factor in the pathogenesis of rheumatoid arthritis: prospects for therapeutic intervention," Mediators of Inflammation, vol. 2008, Article ID 129873, 6 pages, 2008 . 
[163] L. C. Huber, O. Distler, I. Tarner, R. E. Gay, S. Gay, and T. Pap, "Synovial fibroblasts: key players in rheumatoid arthritis," Rheumatology, vol. 45, no. 6, pp. 669-675, 2006.

[164] I. Meinecke, E. Rutkauskaite, S. Gay, and T. Pap, "The role of synovial fibroblasts in mediating joint destruction in rheumatoid arthritis," Current Pharmaceutical Design, vol. 11, no. 5, pp. 563-568, 2005.

[165] C. J. Wruck, A. Fragoulis, A. Gurzynski et al., "Role of oxidative stress in rheumatoid arthritis: insights from the Nrf2-knockout mice," Annals of the Rheumatic Diseases, vol. 70, no. 5, pp. 844850, 2011.

[166] C. J. Wruck, M. E. Götz, T. Herdegen, D. Varoga, L.-O. Brandenburg, and T. Pufe, "Kavalactones protect neural cells against amyloid $\beta$ peptide-induced neurotoxicity via extracellular signal-regulated kinase 1/2-dependent nuclear factor erythroid 2-related factor 2 activation," Molecular Pharmacology, vol. 73, no. 6, pp. 1785-1795, 2008.

[167] A. K. Jaiswal, "Nrf2 signaling in coordinated activation of antioxidant gene expression," Free Radical Biology \& Medicine, vol. 36, no. 10, pp. 1199-1207, 2004.

[168] D. J. Pattison, A. J. Silman, N. J. Goodson et al., "Vitamin C and the risk of developing inflammatory polyarthritis: prospective nested case-control study," Annals of the Rheumatic Diseases, vol. 63, no. 7, pp. 843-847, 2004.

[169] J. R. Cerhan, K. G. Saag, L. A. Merlino, T. R. Mikuls, and L. A. Criswell, "Antioxidant micronutrients and risk of rheumatoid arthritis in a cohort of older women," American Journal of Epidemiology, vol. 157, no. 4, pp. 345-354, 2003.

[170] D. J. Pattison, D. P. M. Symmons, M. Lunt et al., "Dietary risk factors for the development of inflammatory polyarthritis: evidence for a role of high level of red meat consumption," Arthritis \& Rheumatism, vol. 50, no. 12, pp. 3804-3812, 2004.

[171] N. Udagawa, S. Kotake, N. Kamatani, N. Takahashi, and T. Suda, "The molecular mechanism of osteoclastogenesis in rheumatoid arthritis," Arthritis Research, vol. 4, no. 5, pp. 281289, 2002.

[172] S. Y. Bu, M. Lerner, B. J. Stoecker et al., "Dried plum polyphenols inhibit osteoclastogenesis by downregulating NFATcl and inflammatory mediators," Calcified Tissue International, vol. 82, no. 6, pp. 475-488, 2008.

[173] Y.-H. He, J. Zhou, Y.-S. Wang et al., "Anti-inflammatory and anti-oxidative effects of cherries on Freund's adjuvant-induced arthritis in rats," Scandinavian Journal of Rheumatology, vol. 35, no. 5, pp. 356-358, 2006.

[174] M. G. F. Wahba, B. A. S. Messiha, and A. A. Abo-Saif, "Protective effects of fenofibrate and resveratrol in an aggressive model of rheumatoid arthritis in rats," Pharmaceutical Biology, vol. 54, no. 9, pp. 1705-1715, 2015.

[175] M. Tsubaki, T. Takeda, T. Kino et al., "Mangiferin suppresses CIA by suppressing the expression of TNF- $\alpha$, IL- 6 , IL- $1 \beta$, and RANKL through inhibiting the activation of NF- $\kappa$ B and ERK1/2," American Journal of Translational Research, vol. 7, no. 8, pp. 1371-1381, 2015.

[176] P. Luczkiewicz, A. Kokotkiewicz, A. Dampc, and M. Luczkiewicz, "Mangiferin: a promising therapeutic agent for rheumatoid arthritis treatment," Medical Hypotheses, vol. 83, no. 5, pp. 570$574,2014$.

[177] V. Natarajan, B. Madhan, and M. L. Tiku, "Intra-articular injections of polyphenols protect articular cartilage from inflammation-induced degradation: suggesting a potential role in cartilage therapeutics," PLoS ONE, vol. 10, no. 6, Article ID e0127165, 20 pages, 2015.
[178] H.-Y. Yoon, E.-G. Lee, H. Lee et al., "Kaempferol inhibits IL- $1 \beta$-induced proliferation of rheumatoid arthritis synovial fibroblasts and the production of COX-2, PGE2 and MMPs," International Journal of Molecular Medicine, vol. 32, no. 4, pp. 971-977, 2013.

[179] M. Comalada, D. Camuesco, S. Sierra et al., "In vivo quercitrin anti-inflammatory effect involves release of quercetin, which inhibits inflammation through down-regulation of the NF- $\kappa \mathrm{B}$ pathway," European Journal of Immunology, vol. 35, no. 2, pp. 584-592, 2005.

[180] G. Schett, M. Tohidast-Akrad, J. S. Smolen et al., "Activation, differential localization, and regulation of the stress-activated protein kinases, extracellular signal-regulated kinase, c-Jun Nterminal kinase, and p38 mitogen-activated protein kinase, in synovial tissue and cells in rheumatoid arthritis," Arthritis \& Rheumatism, vol. 43, no. 11, pp. 2501-2512, 2000.

[181] S. J. Pragasam, V. Venkatesan, and M. Rasool, "Immunomodulatory and anti-inflammatory effect of p-coumaric acid, a common dietary polyphenol on experimental inflammation in rats," Inflammation, vol. 36, no. 1, pp. 169-176, 2013.

[182] J. Wang, Q. Zhang, S. Jin, D. He, S. Zhao, and S. Liu, "Genistein modulate immune responses in collagen-induced rheumatoid arthritis model," Maturitas, vol. 59, no. 4, pp. 405-412, 2008.

[183] D. J. Pattison, D. P. M. Symmons, M. Lunt et al., "Dietary $\beta$ cryptoxanthin and inflammatory polyarthritis: results from a population-based prospective study," The American Journal of Clinical Nutrition, vol. 82, no. 2, pp. 451-455, 2005.

[184] I. Avalos, C. P. Chung, A. Oeser et al., "Increased augmentation index in rheumatoid arthritis and its relationship to coronary artery atherosclerosis," The Journal of Rheumatology, vol. 34, no. 12, pp. 2388-2394, 2007.

[185] A. Cypiene, A. Laucevicius, A. Venalis et al., "Non-invasive assessment of arterial stiffness indices by applanation tonometry and pulse wave analysis in patients with rheumatoid arthritis treated with TNF- $\alpha$ blocker remicade (infliximab)," Proceedings Western Pharmacology Society, vol. 50, pp. 119-122, 2007.

[186] M. A. Crilly and G. McNeill, "Arterial dysfunction in patients with rheumatoid arthritis and the consumption of daily fruits and daily vegetables," European Journal of Clinical Nutrition, vol. 66, no. 3, pp. 345-352, 2012.

[187] G. Ramadan and O. El-Menshawy, "Protective effects of gingerturmeric rhizomes mixture on joint inflammation, atherogenesis, kidney dysfunction and other complications in a rat model of human rheumatoid arthritis," International Journal of Rheumatic Diseases, vol. 16, no. 2, pp. 219-229, 2013.

[188] G. Ramadan, M. A. Al-Kahtani, and W. M. El-Sayed, "Antiinflammatory and anti-oxidant properties of Curcuma longa (turmeric) versus Zingiber officinale (ginger) rhizomes in rat adjuvant-induced arthritis," Inflammation, vol. 34, no. 4, pp. 291-301, 2011.

[189] B. Rathi, S. Bodhankar, V. Mohan, and P. Thakurdesai, "Ameliorative effects of a polyphenolic fraction of Cinnamomum zeylanicum L. bark in animal models of inflammation and arthritis," Scientia Pharmaceutica, vol. 81, no. 2, pp. 567-589, 2013.

[190] B. Kloesch, T. Becker, E. Dietersdorfer, H. Kiener, and G. Steiner, "Anti-inflammatory and apoptotic effects of the polyphenol curcumin on human fibroblast-like synoviocytes," International Immunopharmacology, vol. 15, no. 2, pp. 400-405, 2013.

[191] R. Woodrick and E. M. Ruderman, "Anti-interleukin-6 therapy in rheumatoid arthritis," Bulletin of the NYU Hospital for Joint Diseases, vol. 68, no. 3, pp. 211-217, 2010. 
[192] H. Liu and R. M. Pope, "The role of apoptosis in rheumatoid arthritis," Current Opinion in Pharmacology, vol. 3, no. 3, pp. 317-322, 2003.

[193] A. Soultati, G. Mountzios, C. Avgerinou et al., "Endothelial vascular toxicity from chemotherapeutic agents: preclinical evidence and clinical implications," Cancer Treatment Reviews, vol. 38, no. 5, pp. 473-483, 2012.

[194] L. Zeng, Z. Yan, S. Ding, K. Xu, and L. Wang, "Endothelial injury, an intriguing effect of methotrexate and cyclophosphamide during hematopoietic stem cell transplantation in mice," Transplantation Proceedings, vol. 40, no. 8, pp. 26702673, 2008.

[195] H. Sankrityayan and A. S. Majumdar, "Curcumin and folic acid abrogated methotrexate induced vascular endothelial dysfunction," Canadian Journal of Physiology and Pharmacology, vol. 94, no. 1, pp. 89-96, 2015.

[196] Z. Zheng, Y. Sun, Z. Liu, M. Zhang, C. Li, and H. Cai, “The effect of curcumin and its nanoformulation on adjuvant-induced arthritis in rats," Drug Design, Development and Therapy, vol. 9, pp. 4931-4942, 2015.

[197] C. Delgado and J.-X. Guinard, "How do consumer hedonic ratings for extra virgin olive oil relate to quality ratings by experts and descriptive analysis ratings?" Food Quality and Preference, vol. 22, no. 2, pp. 213-225, 2011.

[198] M. Á. Rosillo, M. J. Alcaraz, M. Sánchez-Hidalgo, J. G. Fernández-Bolaños, C. Alarcón-de-la-Lastra, and M. L. Ferrándiz, "Anti-inflammatory and joint protective effects of extra-virgin olive-oil polyphenol extract in experimental arthritis," Journal of Nutritional Biochemistry, vol. 25, no. 12, pp. 1275-1281, 2014.

[199] J. Morel and F. Berenbaum, "Signal transduction pathways: new targets for treating rheumatoid arthritis," Joint Bone Spine, vol. 71, no. 6, pp. 503-510, 2004.

[200] Z. Han, D. L. Boyle, A. M. Manning, and G. S. Firestein, "AP1 and NF- $\kappa \mathrm{B}$ regulation in rheumatoid arthritis and murine collagen-induced arthritis," Autoimmunity, vol. 28, no. 4, pp. 197-208, 1998.

[201] S.-Y. Min, M. Yan, S. B. Kim et al., "Green tea epigallocatechin3-gallate suppresses autoimmune arthritis through indoleamine-2,3-dioxygenase expressing dendritic cells and the nuclear factor, erythroid 2-like 2 antioxidant pathway," Journal of Inflammation, vol. 12, no. 1, article 53, 15 pages, 2015.

[202] C.-H. Yoon, S.-J. Chung, S.-W. Lee, Y.-B. Park, S.-K. Lee, and M.-C. Park, "Gallic acid, a natural polyphenolic acid, induces apoptosis and inhibits proinflammatory gene expressions in rheumatoid arthritis fibroblast-like synoviocytes," Joint Bone Spine, vol. 80, no. 3, pp. 274-279, 2013.

[203] Y. Oka, S. Iwai, H. Amano et al., "Tea polyphenols inhibit rat osteoclast formation and differentiation," Journal of Pharmacological Sciences, vol. 118, no. 1, pp. 55-64, 2012.

[204] P. S. Burrage, K. S. Mix, and C. E. Brinckerhoff, "Matrix metalloproteinases: role in arthritis," Frontiers in Bioscience, vol. 11, no. 1, pp. 529-543, 2006.

[205] M. D. Mossalayi, J. Rambert, E. Renouf, M. Micouleau, and J. M. Mérillon, "Grape polyphenols and propolis mixture inhibits inflammatory mediator release from human leukocytes and reduces clinical scores in experimental arthritis," Phytomedicine, vol. 21, no. 3, pp. 290-297, 2014.

[206] M. Mueller, S. Hobiger, and A. Jungbauer, "Anti-inflammatory activity of extracts from fruits, herbs and spices," Food Chemistry, vol. 122, no. 4, pp. 987-996, 2010. 


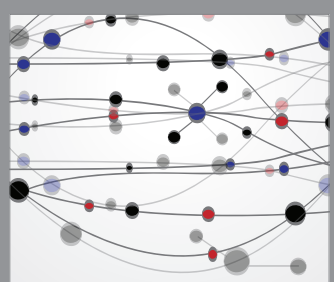

The Scientific World Journal
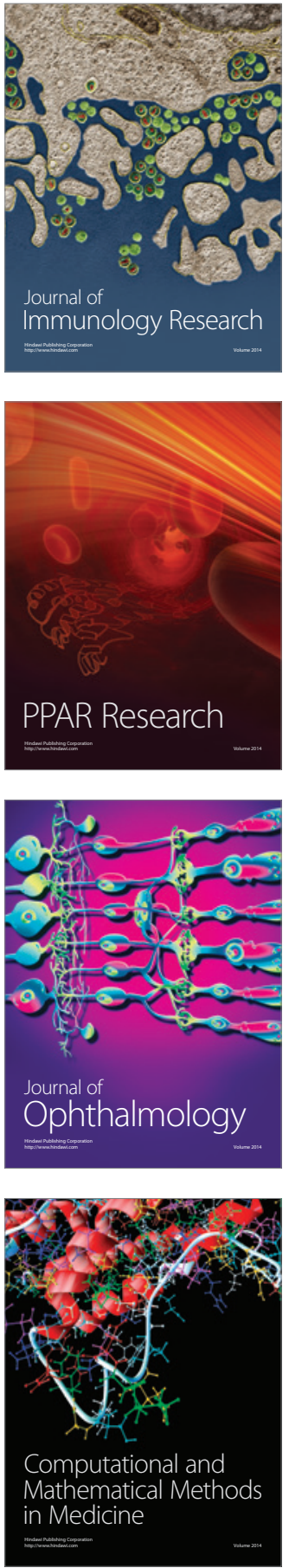

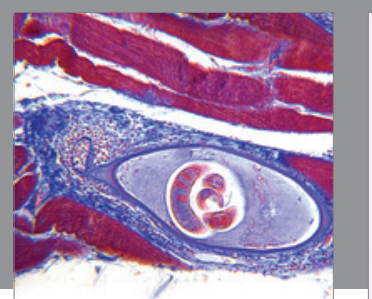

Gastroenterology Research and Practice

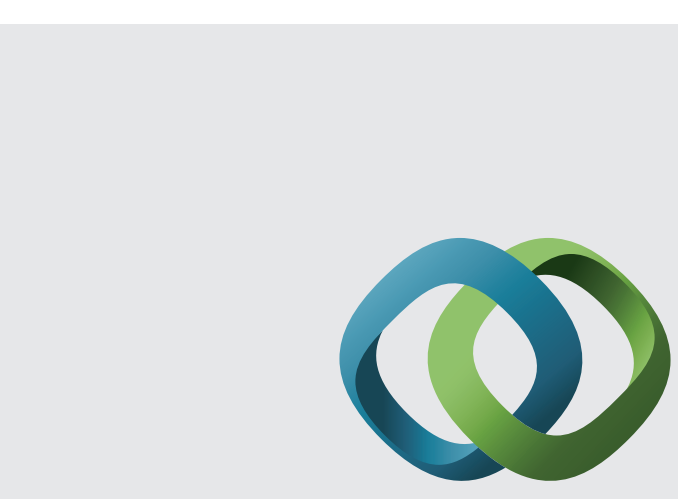

\section{Hindawi}

Submit your manuscripts at

http://www.hindawi.com
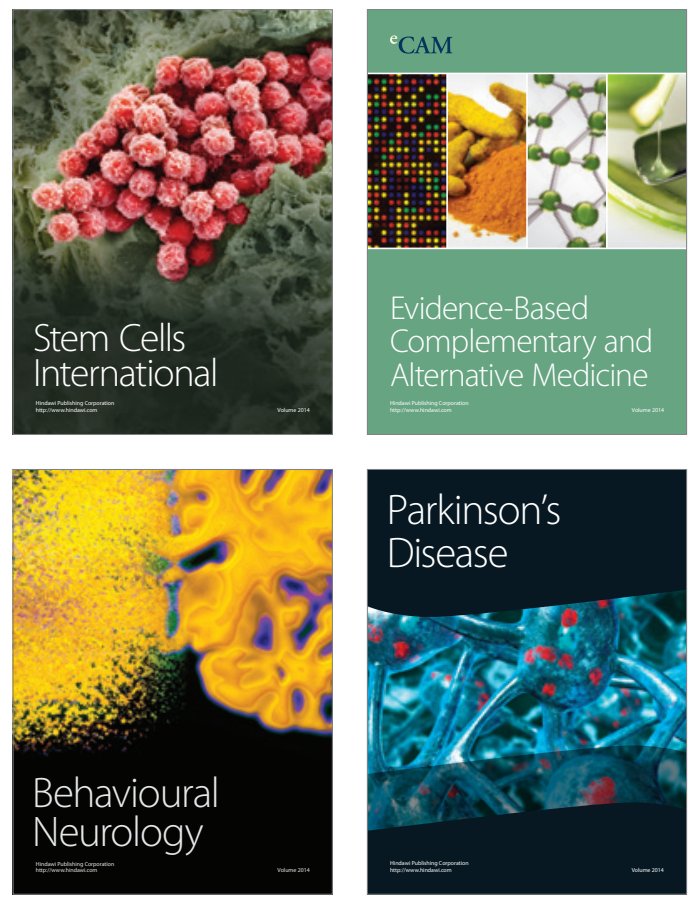
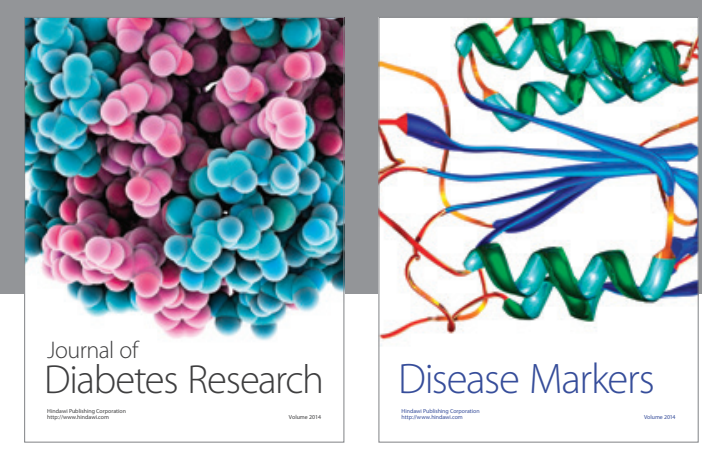

Disease Markers
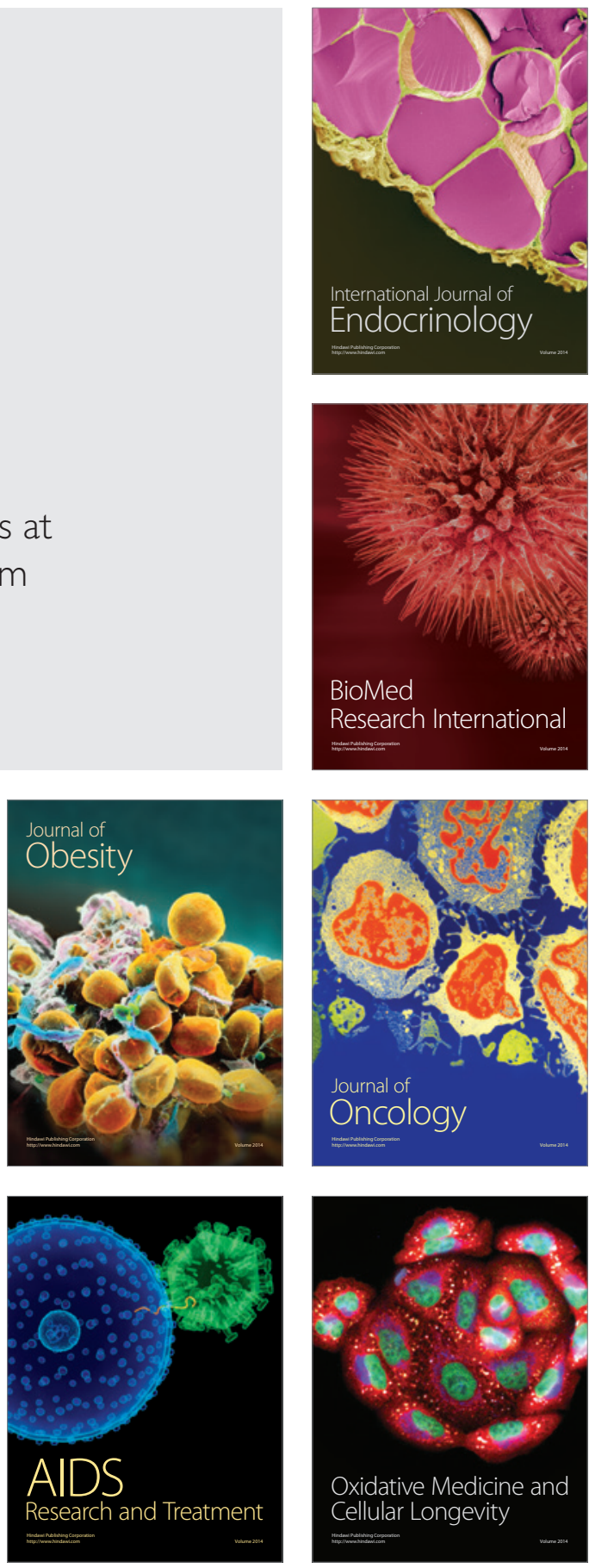